\title{
Microseismic monitoring illuminates phases of slope failure in soft soils
}

\author{
G. Yfantis ${ }^{1}$, S. Pytharouli ${ }^{1}$, R.J. Lunn ${ }^{1}$ and H.E.M. Carvajal ${ }^{2}$ \\ ${ }^{1}$ Department of Civil and Environmental Engineering, University of Strathclyde \\ ${ }^{2}$ Department of Civil and Environmental Engineering, University of Brasilia \\ Corresponding author: Stella Pytharouli (stella.pytharouli@strath.ac.uk)
}

\begin{abstract}
The role of microseismic monitoring in rock slope stability has been long established: large microseismic events associated with rock failure can be detected by seismometers, even at distances of a few kilometres from the source. This is a favourable characteristic for the monitoring of mountainous areas prone to failure. We show that microseismic monitoring, using short-period arrays and a sufficiently high sampling rate, can also record weak precursory signals, that could represent early phases of a larger scale slope failure in soft soils. We validate this hypothesis with field observations. We find that, even in high attenuation material such as clays, it is possible to record and detect in the frequency domain, soil failures at source-to-receiver distances up to $10 \mathrm{~m}$ for crack formation/propagation to more than $43 \mathrm{~m}$ for small (less than $2.5 \mathrm{~m}^{3}$ ) events. Our results show for the first time, an extended frequency range $(10 \mathrm{~Hz}$ to $380 \mathrm{~Hz})$ where small soil failures can be detected at short monitoring distances, even at sites with high background noise levels. This is the first published study focusing on ground-truthed only, slope failure induced seismic signals in soft soils at field scale and within the seismic frequency range (1 $-500 \mathrm{~Hz}$ ). We suggest that microseismic monitoring could complement existing monitoring techniques to characterize the response and structural integrity of earth structures, such as embankments, where the monitoring distances are a few 10 s of metres, with the potential to detect any material deterioration at the very early stages. This study does not focus on automatic classification of slope failure signals, however, our observations and methodology could form the basis for the future development of such an approach.
\end{abstract}

Keywords: microseismic monitoring, soft soils, instability, crack formation, crack propagation

\section{Introduction}

The role of microseismic monitoring (or microseismics) in failure of rock slopes has been extensively studied in recent years, e.g., Spillmann et al., 2007; Barla et al., 2010; Helmstetter and Garambois, 2010; Fischer et al., 2020. It has been found to successfully monitor stability and detect rockfalls through recording of induced microseismic events (Amitrano et al., 2005; Senfaute et al., 2009; Lévy et al., 2011; Gigli et al., 2011; Walter et al., 2012; Arosio et al., 2015). In general, the effectiveness of microseismic monitoring is enhanced by the brittle nature of rock and there being sufficiently large energy emitted by 
rock impacts and the friction of the sliding rock mass on the ground surface. These attributes, along with the ability to deploy well outside the unstable area, has made microseismic monitoring a favourable option amongst engineers and geoscientists.

Today's challenges arise from the urbanization of areas that wouldn't necessarily have been historically habitable, such as those susceptible to slope failure. This increased urbanisation, combined with the increasing frequency and magnitude of natural disasters related to climate change, dictate the need to improve the way we ensure resilient infrastructure. Advancement of monitoring techniques and their adaptation to current conditions is required. Whiteley et al. (2019) reviewed different approaches based on geophysical monitoring of moisture-induced landslides. The authors present a lengthy review of both active (refraction, surface waves) and passive seismic (horizontal to vertical ratio, microseismicity, ambient noise cross correlation, ambient noise tomography) methods that have been identified to provide useful information on landslides. Each method has strengths and limitations with different spatial and temporal resolutions and modes of data acquisition (time-discrete or continuous) and the choice between them depends on field conditions, project requirements and the type of information sought to be found. In microseismic monitoring applications, which is the focus of this paper, limitations are mainly related to the detection of weak seismic signals above noise levels.

High seismic frequencies attenuate faster than low seismic frequencies (Li and Zhao, 2014). Smaller earthquakes, i.e. smaller instabilities and failures, have higher frequency content (Tosi et al., 2012) and as such, are more difficult to detect as the distance from the hypocenter increases. This is the reason why microseismic monitoring is most successful in cases of large rock failures, i.e. for the detection of signals originating by brittle failure and with sufficient magnitude ( $M>1$ ), even at heavily trafficked areas (Zimmer and Sittar, 2015). Consequently, most recent approaches in the international literature that focus on the characterization of a sliding mass using microseismic recordings (e.g. Guinau et al., 2019), including seismic noise recordings (e.g. Lévy et al., 2010) or the automatic detection and classification of microseismic signals emitted by slope instability, are tuned for slopes consisting of brittle material, i.e. rocks (Dammeier et al., 2016).

For soft soils, geophysical properties have been used to study kinematics and rheology characteristics. Ambient seismic noise monitoring has been proposed by Mainsant et al. (2012) as an efficient way to predict failure based on observed changes of the seismic velocity of the failing mass. Seismic noise along with electrical resistivity topography and refraction techniques were also applied for the characterization of a large failed mass in clays by Jongmans et al. (2009). More recently, a study by Fiolleau et al. (2020) presents the investigation of 5 seismic parameters derived from ambient seismic noise monitoring to study precursory signals of rupture in clay. Changes in the velocity of Rayleigh waves during acceleration of the failing mass have been reported by Bertello et al. (2018) in their study of clayey, slow moving landslides. One of the most recent comprehensive studies on the application of microseismic monitoring for soft soils is that of Vouillamoz et al. (2018) where microseismic recordings from clay-rich landslides are detected and classified. Detections also include small fissure and crack formation events. This is particularly important as it is the small events, i.e. crack formation and propagation and local, small scale failures, that are 
of most interest if we are to achieve a warning prior to an imminent slope failure. Such microseismic events are very difficult to detect, mainly because of the weak signal being below, or very close to, noise levels. As a result, the risk of these precursory events remaining undetected, despite the fact that they can represent early signs of material deterioration, is high. This might not be of significant importance for a slope failure at a remote area, but it could be key to preventing a disaster in the case of an earthfill dam or a railway embankment, for example.

In their study, Vouillamoz et al. (2018) are using Sonograms to detect signals of interest which they distinguish from noise if they have been detected by three or more monitoring stations. They then proceed to classify the detected signals into different categories, one of them being cracks and fissures, based on signal characteristics from classification studies published in the international literature (see Vouillamoz et al., 2018 and references therein). None of the cited studies include ground-truthing of the small-inmagnitude events, i.e. cracks, fissures and small instabilities. The conclusions are based on the timing of these events (immediately before a very large failure), and the assumptions that due to the remoteness of the site any non-natural sources are rare-to-non-existent, and that the natural seismic activity of the area is very low. The latter is documented by the lack of reported earthquakes for the region in the seismic catalogue. We do not dispute the validity of the assumptions which are reasonable and highly likely, neither do we disagree with the conclusions, although the absence of earthquakes with magnitudes $M<1.5$ from a seismic catalogue does not necessarily mean they did not occur, but may simply imply they could not be detected.

The difficulty in detecting weak seismic signals could potentially be attributed to four main factors: (1) inadequate instrumentation: small weak events usually have very high frequency content that common seismic instrumentation cannot detect. (2) inefficient signal analysis methodology: in order to suppress noise and detect weak signals, filtering is commonly considered to be a necessary step. Unfortunately, in many cases filtering leads to the removal of not only noise but also of weak signals. (3) lack of actual precursory signals: some failures happen very suddenly, therefore, precursory signals might not exist or might happen very close to the actual failure. And (4) lack of undisputable validation of the interpretation of the recordings rather than implicit assumptions.

In this paper we hypothesize that microseismic monitoring and existing instrumentation, i.e. short-period seismometers, can be successfully used to monitor slope failure even in soft soils where signal attenuation is high. Short-period seismometers, used for local, temporary seismic monitoring networks, are sensitive to microseismic events $(-3<$ $\mathrm{M}<2$ ). They have successfully been used in monitoring of large rockslides and landslides (Tonnellier et al., 2013; Provost et al., 2017; Vouillamoz et al., 2018). We apply commonly used spectral analysis techniques to analyse recorded signals during two controlled induced slope failures and we validate detections with visual observations. More advanced analysis techniques were not required for our study but such approaches might be necessary for the next step, i.e. automatic detection and classification of signals. To our knowledge, this is the first study at field scale that provides validated (ground-truthed) evidence of very weak 
seismic signals that represent different failure modes, including crack formation and propagation in soft soil.

\section{Methodology}

\subsection{Field Experimental set-up}

Field site: Two adjacent vertical slope faces, hereafter referred to as Vertical Face 1 (VF1) and Vertical Face 2 (VF2; see Figure 1), respectively, were created by a rectangular excavation of dimensions L:14m, W:6m and D:2.5m. Each face was $2.5 \mathrm{~m}$ high and $3 \mathrm{~m}$ wide. The field site was located at a non-residential area (see fig. 1a) in the northern part of Brasilia (Brazil) at a distance of more than $5 \mathrm{~km}$ from the closest water body to the East (Paranoa Lake), and at a minimum $1.2 \mathrm{~km}$ radius from a motorway (to the West) and populated area (to the East). The ground surface of the site was flat, partially covered by low vegetation and some trees. The top geological layer consisted mainly of unsaturated highly porous tropical clay (porosity > 55\%; Otálvaro et al., 2015), found in the high plain of Central Brazil, to a depth of more than $20 \mathrm{~m}$. Typical for this type of soil friction angle values are between 2431 degrees. Geophysical surveys conducted at the area of the site suggested Vp values between $0.3-1.2 \mathrm{~km} / \mathrm{s}$ for the first $20 \mathrm{~m}$ below ground surface (fig. 4.113-4.115 in Silva, 2011).

Experiment: An experiment on the induced failure of the two vertical faces took place on a Saturday afternoon between 19:00h-24:00h. Background noise from activities in the surrounding area, e.g. traffic, was present but at lower levels compared to the levels during day hours. Works at a construction site immediately to the west of the excavation (see fig. 1b) stopped by 17:00h, therefore did not contribute to the background noise at the site at the time of the experiment. All parameters, i.e. local geology, location and geometry of the microseismic network used for monitoring, and the methodology used to induce failure, remained the same for the total duration of the field measurement..

Failure was induced at each face separately by increasing the vertical load at its crown. The design of the loading mechanism (Figure 1c, d) aimed to add as little as possible to the background seismic noise. There were three in-line reinforced concrete piles (reaction piles), $0.65 \mathrm{~m}$ diameter and $12 \mathrm{~m}$ deep, at $3 \mathrm{~m}$ spacing. The reinforcement, four construction steel bars, were left exposed by $1.5 \mathrm{~m}$ above the ground. A rigid, I-shaped steel beam was placed on top of the piles. The beam was supported by wooden stands with the construction steel of the piles welded around it to restrict movement. Below the beam, a soil area of $1 \mathrm{~m}^{2}$ was levelled in between each pair of consecutive piles. A rigid $1 \mathrm{~m}^{2}$ square metallic plate was placed on the level surface. This formed the base for the installation of a hydraulic jack, which was in turn connected to a manually operated oil pump. The oil pump was placed on a soft cushion. An additional cushion was placed between the handle and the body of the pump. This aimed to minimize the vibrations caused by the pump. By increasing the pressure of the oil, the hydraulic jack was pushed against the metallic beam and consequently the soil surface, thus increasing the applied load on the crown of the slope. All parts of the loading mechanism were levelled to ensure that the load was applied vertically. At times when parts of the loading mechanism were found to deviate from vertical, the experimental process was paused to restore verticality. A measuring tape, attached to the hydraulic jack and the metallic beam, was used to monitor the induced vertical displacement on the crown of the 
vertical face. Vertical displacement was recorded manually. The corresponding times were provided by a GPS clock. Only one vertical face was loaded at a time.

Microseismic monitoring was carried out using 11 short-period 3-component seismometers (Sercel L4C-3D) with a flat spectrum response between $2 \mathrm{~Hz}$ and $100 \mathrm{~Hz}$. A dense deployment geometry was adopted to maximize detection of all types of potential events, e.g. crack formation and propagation, and failure events. The location of all seismometers used, relative to the location of the vertical slope faces, can be seen in Figure 2. The field site was a construction site and due to space restrictions, we were not able to deploy any seismometers to the west side of the excavation. The chosen deployment configuration formed a dense microseismic network with approximately $5 \mathrm{~m}$ to $10 \mathrm{~m}$ spacing. As shown in Figure 2, this configuration of the monitoring network resulted from the formation of two tripartite microseismic arrays, each consisting of 4 sensors, with aperture size $10 \mathrm{~m}$ and $20 \mathrm{~m}$ (fig. 2), respectively. This deployment geometry, originally suggested by Joswig (2008), has been used by a number of previously published studies, e.g. Vouillamoz et al. (2018); Tonnellier et al. (2013), for clayey landslide monitoring. Part of the network also formed a linear array consisting of sensors at distances $10 \mathrm{~m}, 15 \mathrm{~m}, 20 \mathrm{~m}$ and $30 \mathrm{~m}$ from the excavation and allowing for studying attenuation effects. Finally, one seismometer (No 11) was placed inside the excavation at a different elevation than the rest. This was done to study any differences between deployment of sensors behind and in front of a landslide's face and to assure that the smallest failures expected to emit weaker signals would be recorded. Unfortunately, due to malfunction, we were not able to acquire any data from that seismometer. All seismometers were buried at $50 \mathrm{~cm}$ below the ground surface. The closest distance between a seismometer and the vertical faces was $10 \mathrm{~m}$ to ensure the safety of the sensors.

Recording was done on continuous mode, at a sampling rate of $1000 \mathrm{~Hz}$ using dataloggers (RefTek DAS-130/3). Synchronisation of all recordings was ensured via use of GPS clocks. The North-South component of each seismometer was set perpendicular and the East-West component parallel to the strike of the vertical faces. This orientation does not coincide with the geographical North shown in fig. 2.

Loading commenced on the crown of VF1 following one hour of background noise recordings. The load increase was stepwise, starting from zero, with an additional $10 \mathrm{kN}$ being applied at one-minute intervals. If a vertical displacement was visually observed on the measurement tape, then the load was kept constant until all vertical displacement had ceased and any accompanying cracking on the face had stopped. The load was maintained for a further 60 seconds before resuming normal procedure. This loading strategy ensured no overlap between potential failures and thus clear seismic recordings of individual seismic events. Field notes of visually observed failures, along with photos and video footage, were also taken during the field experiment. All data have the same time reference, through the use of GPS clocks. 
(a)

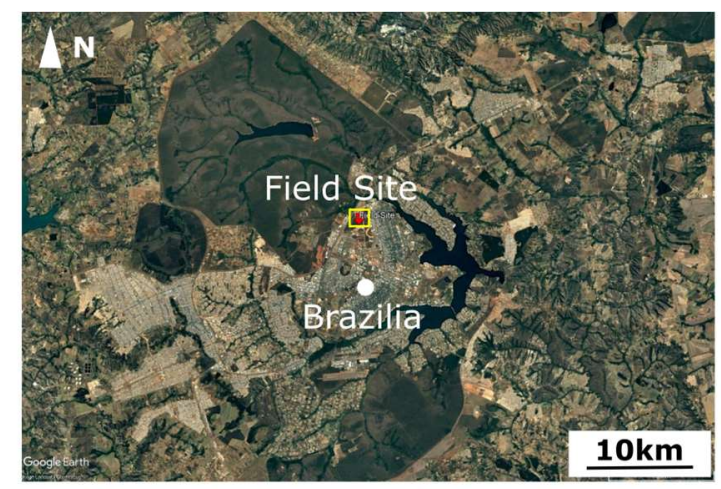

(b)

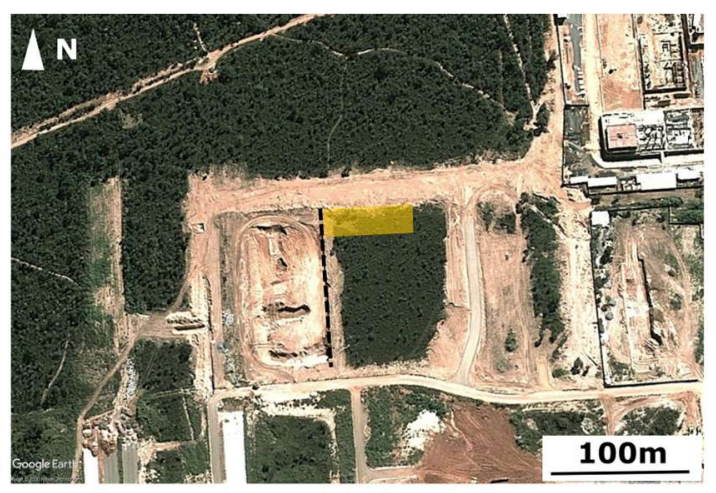

(d)

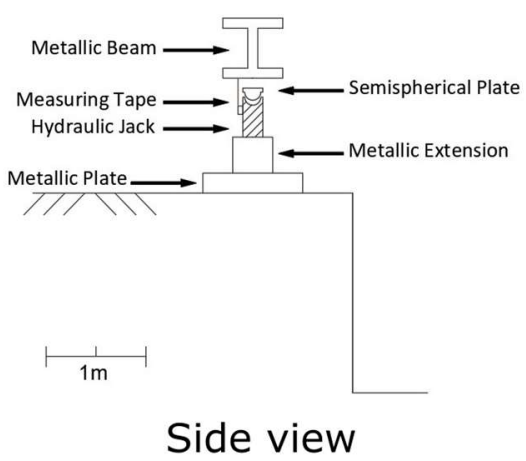

(c)

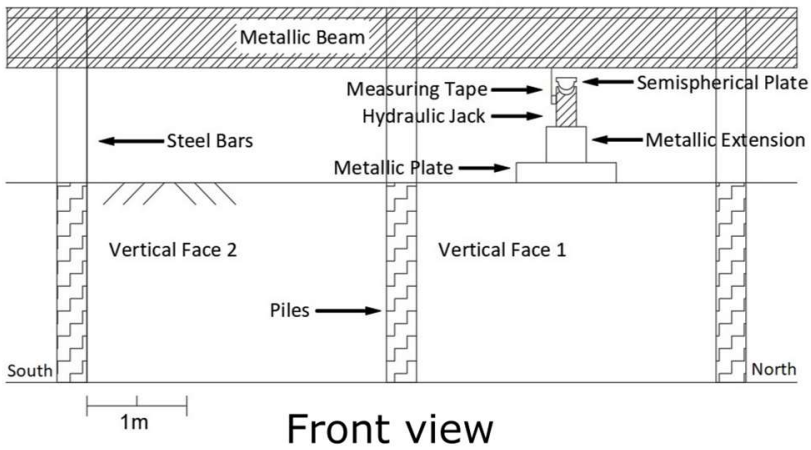

Figure 1. (a) Location map of the field site (indicated by the yellow box) at the north side of the city of Brasilia (from Google Earth maps). (b) Zoomed in map of the area within the yellow box shown in (a). The location of the excavation and microseismic network is shown as the shaded area. Within a couple of metres from the west face of the excavation, there was a fence (black dashed line) of an active construction site (from Google Earth maps). (c) Front View of the loading mechanism and set-up (looking towards West). The location of the three reinforced concrete piles constructed to carry the weight of the metallic beam used for the loading mechanism are also shown. (d) Side view (from South, looking towards North) of the 

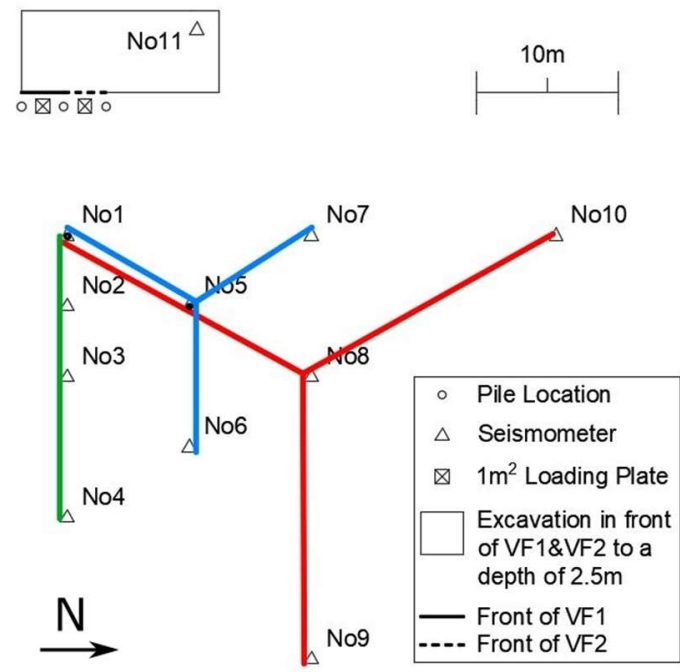

Figure 2. Deployment geometry (plan view) of microseismic network consisting of 11 threecomponent short-period seismometers next to the excavation pit (rectangle). The locations of Vertical Face 1 (VF1) and Vertical Face 2 (VF2) within the excavation pit are also shown. The deployment geometry allowed for the formation of two tripartite arrays of different apertures, $10 \mathrm{~m}$ (shown in blue) and $20 \mathrm{~m}$ (shown in red), respectively and a linear array (shown in green).

\subsection{Analysis of microseismic recordings}

The type of failure (as described in Section 3.1 below) and time of occurrence of all visually observed failure occurrences was determined from the field notes and video footage. We do not make any interpretations. The observed events were then identified in the seismic recordings using the observed time of occurrence. We used spectral analysis in the frequency and the time-frequency domain for the processing of the microseismic recordings that contained the signals of the visually observed failures. Spectral analysis was based on the algorithm proposed by Welch (1967) for the calculation of power spectral density (PSD) (Welch, 1967; Press, 1992). All PSD values were in units of $10 \log _{10}\left(\mathrm{~m}^{2} \mathrm{~s}^{-2} / \mathrm{Hz}\right)[\mathrm{dB}]$. The noise PSD was calculated from a 5 minute interval of the recordings prior to the start of the experiment: The Power Spectral Density (PSD) of short duration noise recordings (4 sec segments of recordings then averaged over a 5 minute total duration) was calculated for each seismometer separately. For the PSDs of the signals, we used a $4 \mathrm{sec}$ window in which we had visual observations that a failure took place. The actual SNR value was calculated by subtracting (since values are in $\mathrm{dB}$, i.e. logarithms) the corresponding value of the noise PSD from the signal PSD. To reflect that the SNR values reported are calculated from PSD values in $\mathrm{dB}$, we use hereafter the term SNR $\mathrm{dB}$. All computations were carried out in Matlab (C).

In this paper, we make no attempt to characterize any other signals present in the recordings that do not correspond to visual observations, i.e. we do not aim to develop a detection/classification methodology for seismic signals originating from slope failure. We only present our findings from the analysis of ground-truthed failure events, focusing on 
providing a proof of concept for the potential of microseismics to detect early stages of slope instability.

\section{Results}

\subsection{Types of observed failures as a result of induced displacement}

We observed three main types of failures:

(1) Crack Formation/Propagation: As the vertical load and displacement on the crown of VF1 increased, cracks started to form. Initially, cracks were observed at the bottom of the vertical slope and they propagated upwards to the crown (Figure 3). During propagation, the part of the cracks that formed first got wider and easier to visually identify. When the cracks reached the crown, propagation stopped with the cracks continuing to grow in width. Unfortunately, this process was observed only at the beginning of the experiment (loading of VF1) due to deteriorating day light conditions. The light from the field lamp used was not adequate to allow for further observations of this kind. We believe that cracks also formed inside the soil mass, but no visual observations are available. As cracks formed and propagated along the surface of VF1, there were 6 times when soil was observed bursting out of them in the form of dust (Figure 3f). We attribute this to the continuous displacement of VF1. The time of occurrence of these soil bursts was recorded and used later for the identification of crack formation/propagation signals within the seismic recordings.

(2) Topple and Fall type failure: this involves soil block toppling and falling (Figure 4) as well as shear within the soil mass, occurring immediately after cracks were fully formed on VF1. The cracks encircled the area where a topple and fall failure subsequently took place as the vertical displacement kept increasing. The cohesion of the soil was retained after the detachment of the soil volume from VF1, with the soil mass forming soil blocks that initially toppled before reaching the ground. This failure type occurred twice during the full duration of the experiment and resulted in the largest failed soil volumes, estimated between $1.8 \mathrm{~m}^{3}$ and $2.5 \mathrm{~m}^{3}$, based on the dimensions of the failed soil mass.

(3) Soil Block Fall type failure (without toppling): This was the most common failure type observed during the field experiment. It involved having parts of both Vertical Faces (VF1 \& VF2) falling inside the excavation (Figure 5). 
(a)

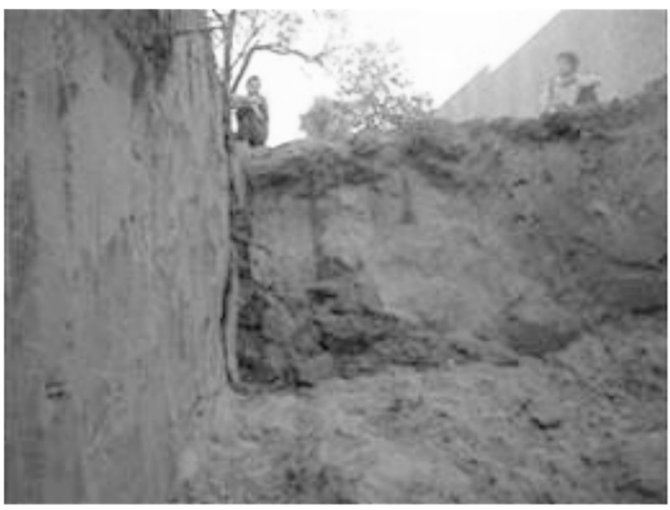

(b)

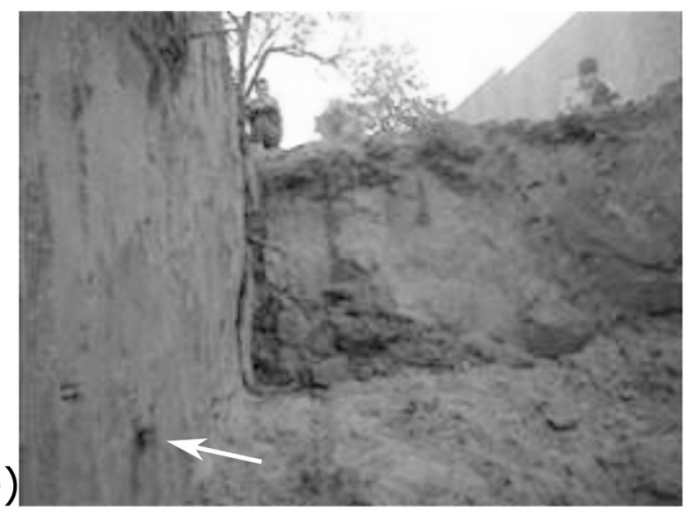

(c)

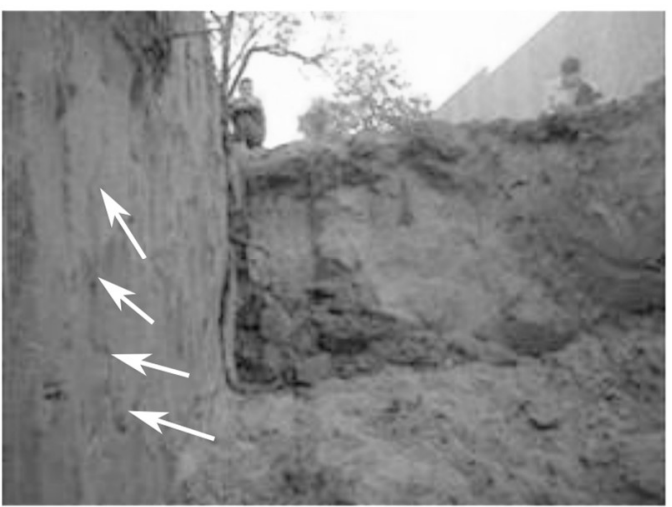

(d)

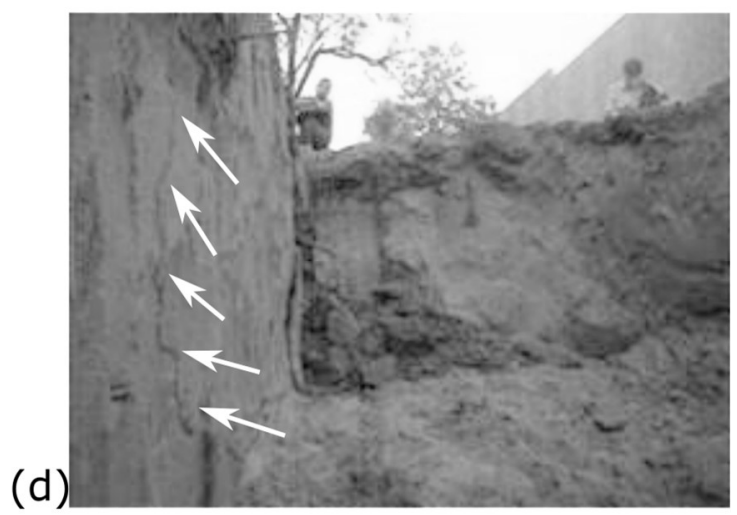

(e)

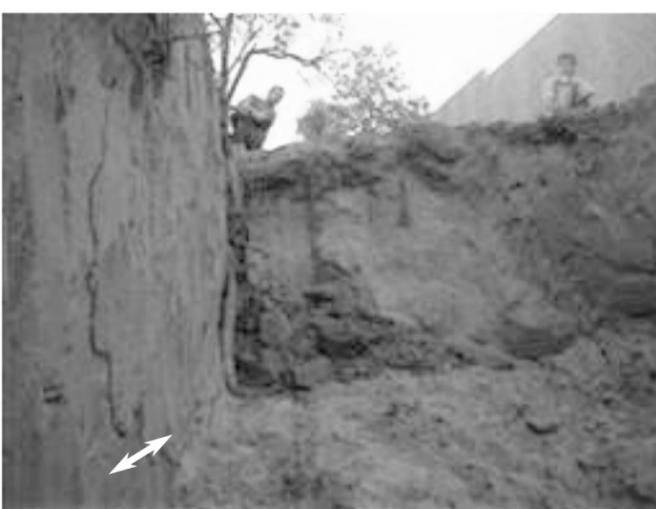

(f)

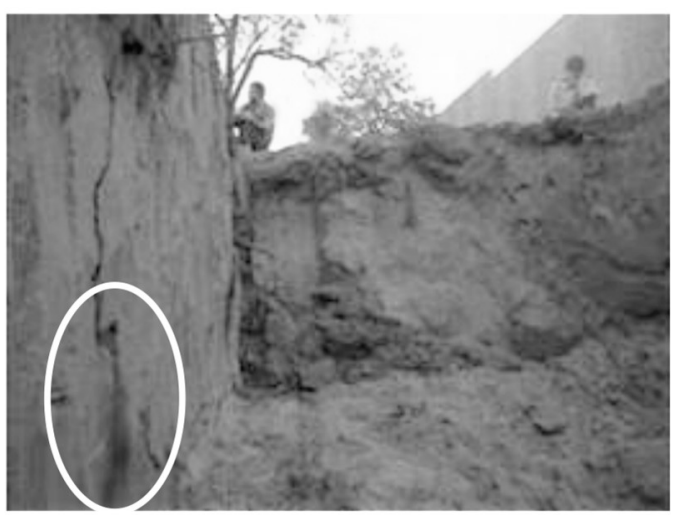

Figure 3: (a) Face of VF1 with no cracks formed. (b - d) Crack formation and propagation events starting from the bottom of VF1 and propagating upwards. (e) As the crack evolved, the parts of the crack that had already formed, got wider. (f) During crack propagation soil bursts were observed. For scale, the full depth of the excavation is $2.5 \mathrm{~m}$ and the photos were taken looking towards the south face of the excavation, with the Vertical faces to the left (towards East). The video of this failure is available as Supplementary material. 
(a)

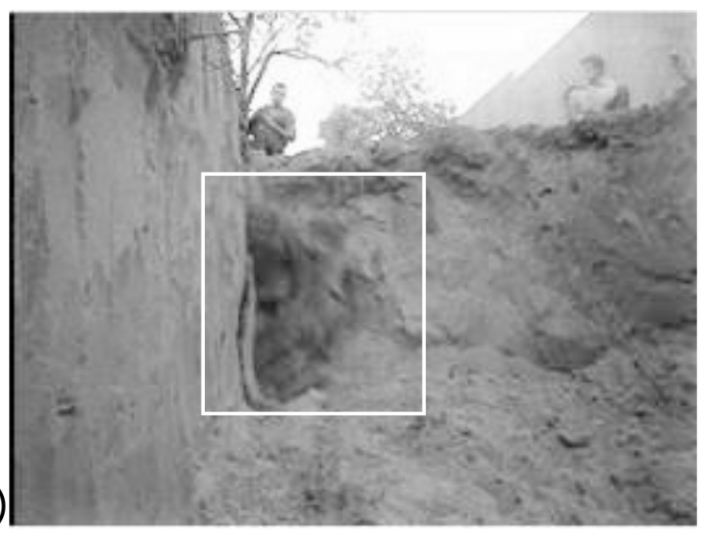

(b)

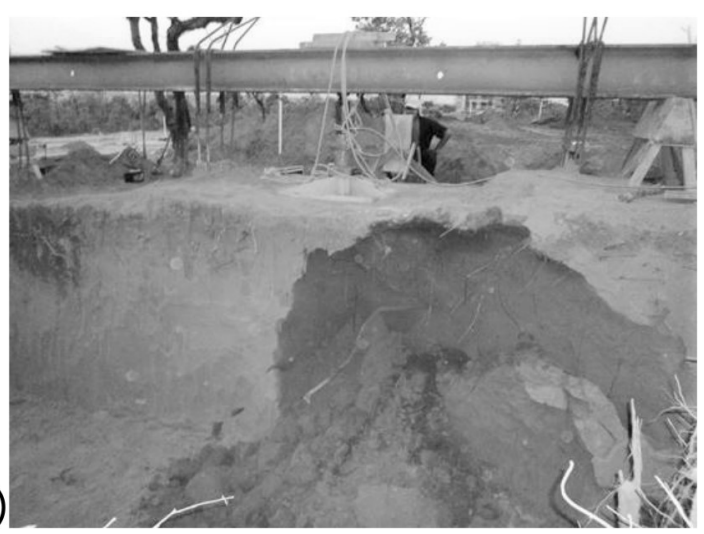

Figure 4: Soil block topple and fall: After cracking, a volume of soil was detached from the vertical face. This type of failure involved soil blocks (a) toppling (area highlighted within the square) and, (b) falling on the ground surface. For scale, the full depth of the excavation is $2.5 \mathrm{~m}$ and the photo in (a) was taken looking towards the south face of the excavation, while the photo in (b) looking towards the North-East direction. (a)

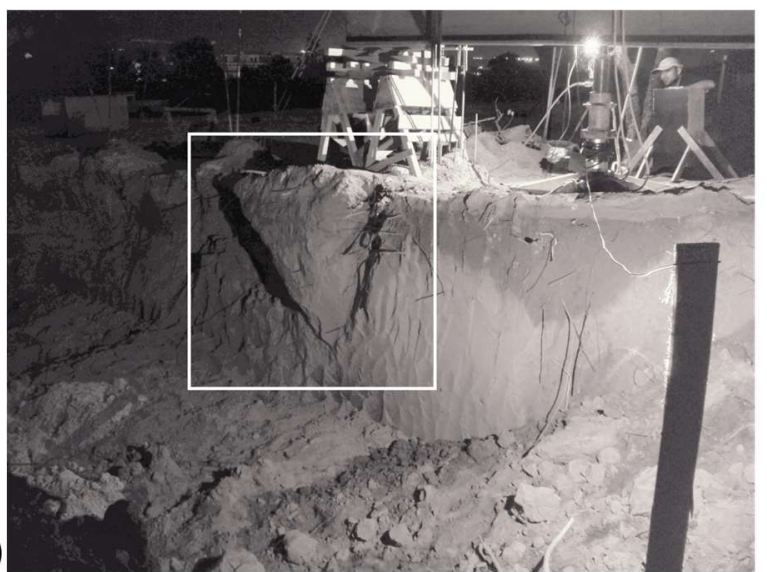
(b)

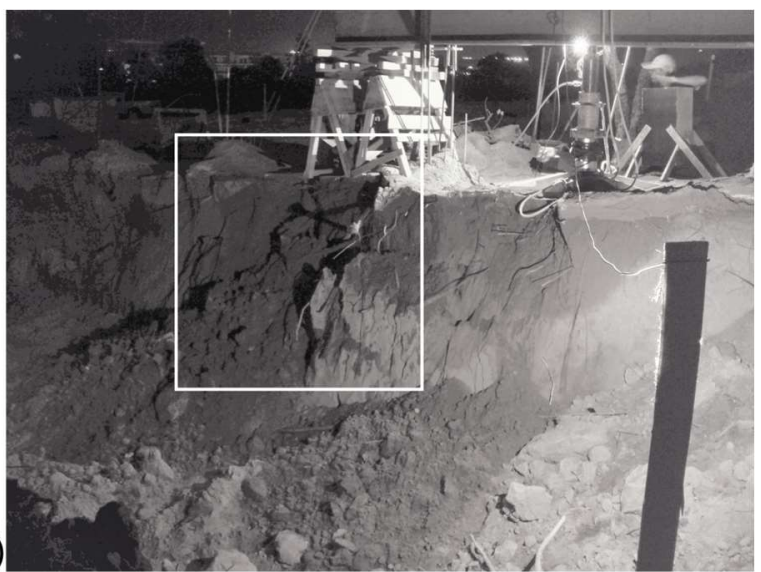

293 Figure 5. Photos of a Soil Block Fall during loading of VF2 (a) before, and (b) after failure. The white box indicates the soil block that fell inside the excavation. This event was the biggest observed for this type of failure. For scale, the full depth of the excavation is $2.5 \mathrm{~m}$ and the photos were taken looking towards the North-East direction. 
The corresponding times of occurrence for all visually observed failures on VF1 and VF2 are shown in Figure 6a,b and d,e respectively. It should be noted that only the larger failure events, i.e. events No 1, 2, 4, 5 and 6 for VF1 and events No 1 and 2 for VF2, can be clearly identified in the time recordings after visual inspection. Crack formation/propagation or small soil block falls did not produce amplitudes that could be distinguished visually above background noise levels in Figures $6 \mathrm{~b}$ and $6 \mathrm{~d}$. The only reason we know their time of occurrence is because of the field observations and log book. Table 1 shows the total number per type of observed failure occurrences during the experiment. There were multiple crack formation/propagation events observed within the first 25 mins of the loading of VF1 (Figures 6a, b), preceding each of the Topple and Fall failure events (events no 1 and 2 in Figure 6a, b).

Table 1. Visually observed failures during loading of both vertical faces. Numbers in brackets indicate the time of occurrence for each failure in minutes from the start of $1^{\text {st }}$ 309 loading for each vertical face.

\begin{tabular}{|l|l|l|l|}
\hline \multicolumn{1}{|c|}{ Face } & \multicolumn{1}{c|}{$\begin{array}{c}\text { Crack } \\
\text { formation/propagation }\end{array}$} & $\begin{array}{c}\text { Soil Block Topple } \\
\text { and Fall }\end{array}$ & \multicolumn{1}{c|}{ Soil Block Fall } \\
\hline VF1 & Multiple & $2(19.48,20.98)$ & $\begin{array}{l}3(31.95,55.55, \\
120.83,120.83)\end{array}$ \\
\hline VF2 & Not conclusive & - & $3(9.88,32.77,37.85)$ \\
\hline
\end{tabular}


(a)

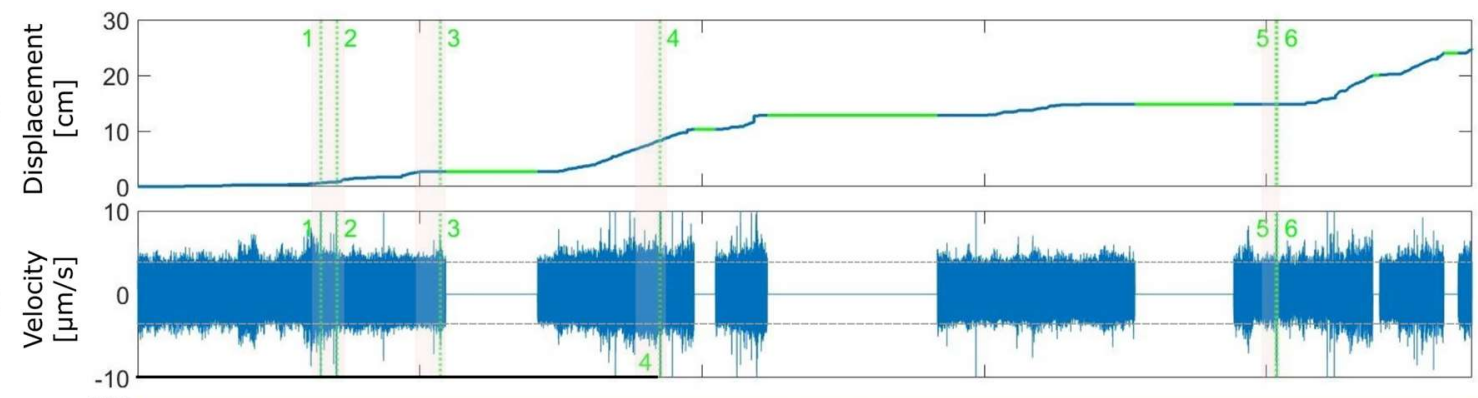

(c)

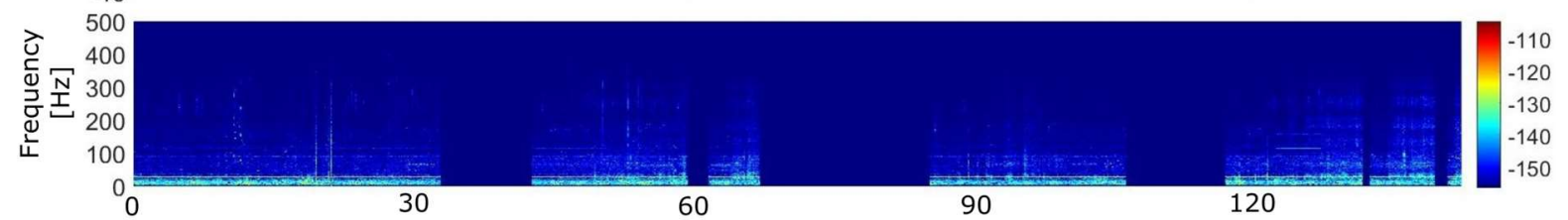

Time since the beginning of loading [minutes]

(d)

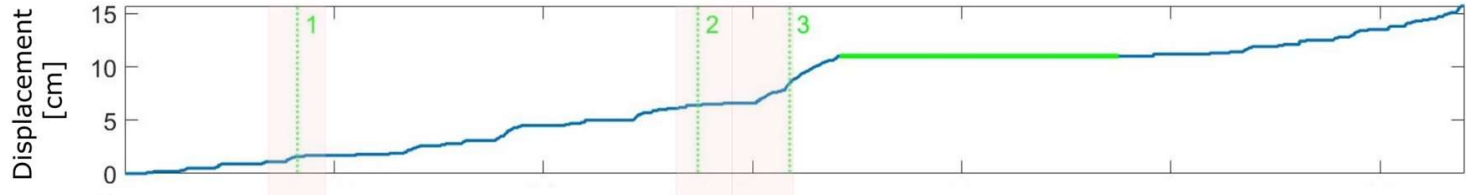

(e)

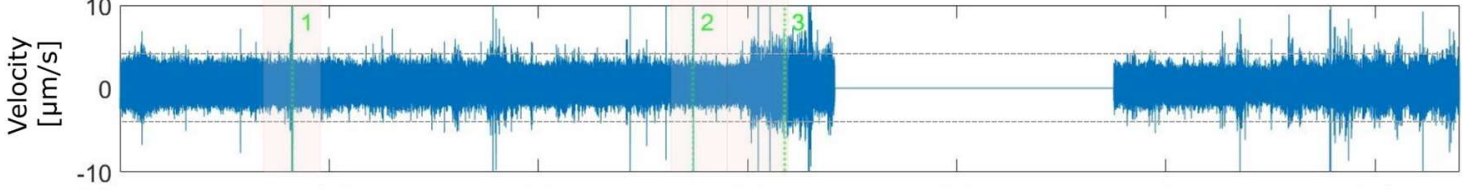

(f)

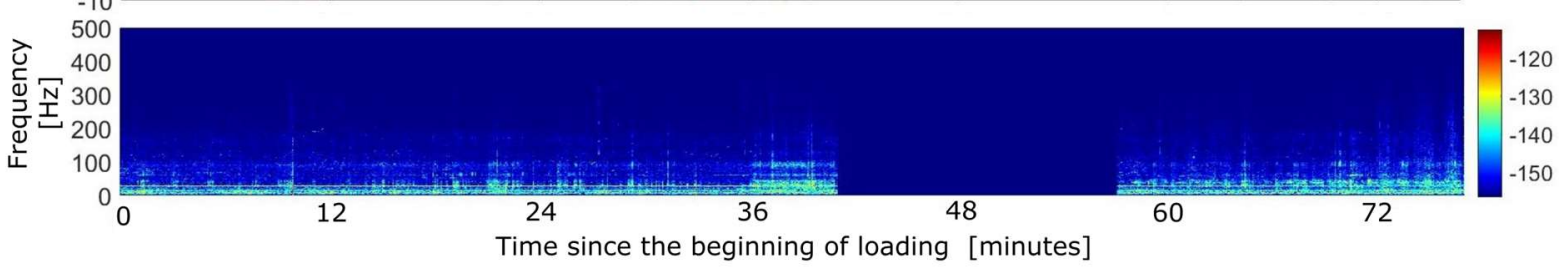

Figure 6. Vertical Face 1 (VF1): (a) Time evolution of induced vertical displacement (blue line). The time origin corresponds to the start time of loading for each vertical face. (b) Time record of the seismic signal for the whole duration of the induced failure as recorded by seismometer No 1 at a distance of 10m from VF1. (c) spectrogram of the full recording for VF1. The colour scale represents Power in [dB]. (d) Same as in (a) but for Vertical Face 2 (VF2). (e) same as in (b) but for VF2. (f) same as in (c) but for VF2. Gaps on the seismic recordings and the green intervals on the vertical displacement curves correspond to time periods when the experiments temporarily had to stop. The dashed horizontal lines in (b) and (d) correspond to $\pm 3 \sigma$ interval for the background noise, equal to $\pm 3.7 \mu \mathrm{m} / \mathrm{s}$. All visually observed failure events are marked with vertical dashed green lines both on the seismic signal records and the vertical displacement curves. (a-b) VF1: Numbers 1 and 2 - "Soil Block Topple and fall". Both were preceded by crack formation/propagation. Numbers 3 to 6 - "Soil block fall", (d-e) VF2: Numbers 1 to 3 - "Soil block fall". The shaded areas represent the windows of the recordings analysed in Figures 8 and 9. 
The failure process for VF1 started with the formation and propagation of cracks, marking an area on the right side of the loading mechanism (time period before Failure 1 in Figure $6 \mathrm{a}, \mathrm{b})$. When these cracks were fully evolved, the enclosed area failed in a complex mechanism of soil block topples and falls. Crack formation/propagation was a continuous phenomenon appearing at the foot of the face, propagating upwards towards the crown. Cracks occurred as a response to the vertical displacements that increased in steps of millimeters. The failed soil mass of the first topple and fall event can be seen in Figure $4 \mathrm{~b}$. This type of event corresponded to the creation of a failure plane starting at the foot of the face and extending all the way up to its crown. A similar failure (Failure 2 in Figure 6a, b) occurred 1.5 min later, on the left side of the loading mechanism. The crack evolution on VF1 before any failure events on the left side of the loading mechanism is shown in Figures 3a-b and 3 f. After these two failures, no further cracks could be visually observed due to poor light conditions. Figure 7 shows the second full failure for VF1 occurring on the left side of the loading mechanism. Other smaller in scale failure events followed; these were formed at least $1 \mathrm{~m}$ above the foot of the face propagating upwards towards the face's crown.

\subsection{Observations on the Induced Failure of Vertical Face 2 (VF2)}

Only small-scale failure events were visually observed on VF2. No crack formation/propagation events could be observed due to the poor lighting conditions. However, progressive failure of the slope appeared to occur in a similar manner to that of VF1 with the largest failure event occurring first. Similar vertical displacement rates were observed for both vertical faces (Figure 6a and 6d).

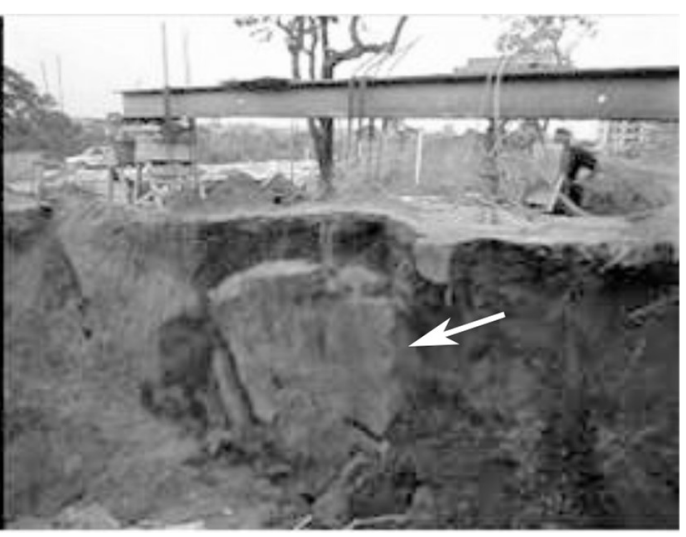

Figure 7. VF1 as seen from a North-East direction during the second soil block topple and fall event (left side of the loading mechanism). An arrow indicates the failing block. For scale, the full depth of the excavation is $2.5 \mathrm{~m}$ and the photo was taken looking towards the NorthEast direction.

\subsection{Time-frequency analysis of visually observed failures}

For the failure events that were visually observed, the recorded time of occurrence was used to identify corresponding signals within the seismic recordings. Figures 8 to 10 show representative spectrograms and seismograms from different parts of the recordings that contain visually observed failure events. These recordings come from seismometer No.1, the 
359 closest sensor to both vertical faces ( $\sim 10 \mathrm{~m}$ away, for location see Figure 2$)$. Seismometer 360 No.1 was chosen because it was the sensor that recorded all visually observed failures 361 clearly, thus allowing better comparisons of the spectral characteristics between the 362 different types of observed failures.

\section{3.3.1. Crack Formation/Propagation and Soil block topple and fall}

364 Figure 8 shows spectrograms calculated from data recorded at all three components of 365 Seismometer No.1, containing the two observed soil block topple and fall failures. These 366 timings are verified by the visually observed times during the experiment on VF1. In the 367 spectrograms, both failures are seen by the lighter coloured lines with frequency content up 368 to $\sim 380 \mathrm{~Hz}$.

369 The time of the weaker but still elevated spectral amplitudes (light blue shaded linear 370 features), visible before the two topple and fall failures, coincides with the observed time of 371 occurrence of crack formation/propagation. The duration of the crack 372 formation/propagation occurrences is shorter, their spectral amplitude weaker and the 373 frequency range over which they can be distinguished above noise is narrower compared to 374 those of the soil block topple and fall failures. 


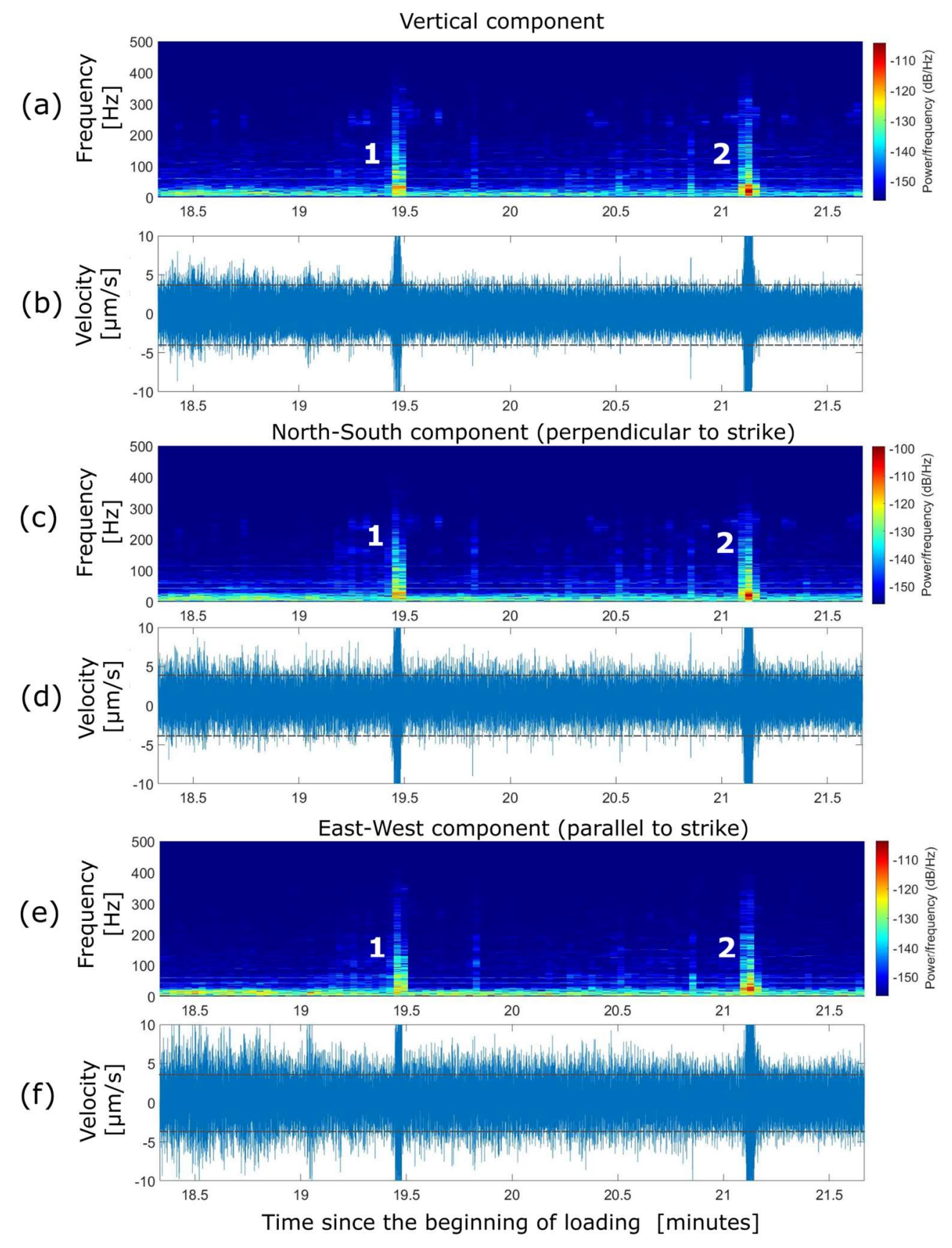

Figure 8. Spectrograms and actual recordings of microseismic data from all three components (a, b: vertical, c, d: North-South - perpendicular to the strike of VF1 and e, f: East-West, parallel to the strike of VF1) of Seismometer No.1, containing the two observed soil block topple and fall failures (Events No 1 and 2 in Figure 6a, b). Numbers 1 and 2 denote 380 the elevated spectral amplitudes (shown as lighter coloured lines compared to the background) representing these two failures in all three spectrograms. The elevated spectral amplitudes, appearing as light blue shaded linear features, before and between the two main failures correspond very well to the time of occurrences of observed cracks forming and 384 propagating. 


\subsubsection{Soil block fall}

Figures 9 and 10 show spectrograms and the corresponding seismograms of recorded data from only the vertical component of seismometer No.1. We found no significant differences with the spectrograms of the horizontal components. The soil block falls are annotated with white arrows. The spectrograms reveal that this type of failure can still be distinguished over a larger range of frequencies, with the upper limit of the frequency content ranging from $60 \mathrm{~Hz}$ (fig. 9a), to $370 \mathrm{~Hz}$ (fig. 10a). The upper limit appears to correlate with:

1) The volume of soil involved in the failure event: The larger the volume of soil involved in the failure event, the larger the overall amplitude of the signal emitted and consequently, the larger the range of frequencies over which the event is distinguishable above noise levels at the monitoring distances implemented in this study.

2) The distance from the initial position of the soil block to the ground surface: The nominal height of VF1 and VF2 was $2.5 \mathrm{~m}$. As repeated failures occurred, soil fell to the ground surface and the face height was gradually reduced. Hence, any failures that occurred closer to the time of complete failure for each vertical face had a shorter travel distance of the failed material to the ground. In addition, the impact was on unconsolidated soil, i.e. soil that had failed earlier. An impact on a 'softer' surface (high absorbance medium) emitted a weaker signal and only the lower frequencies were sufficiently recorded by the seismometer, even at the short distance of $10 \mathrm{~m}$.

The above can be validated by comparing the spectrograms of Failure No.5 in Figure 6a and 6b (Soil Block fall) for VF1 and No.1 (Soil block Fall) in Figure 6d and 6e for VF2. Failure No.6 for VF1 can be distinguished from noise at lower frequencies only (fig. 9c), compared to those of Failure No.1 for VF2 (fig. 10a) due to the smaller volume of soil involved in the failure (i.e. energy at higher frequencies had dissipated below noise levels by the time the signal reached the seismometer), the smaller distance of the fall and the weaker impact on softer ground. The spectrograms of Figures 9a and 10c contain elevated spectral amplitudes (annotated with yellow arrows) that look similar to the annotated failure events (white arrows). There were no visual observations of failures during the times of the yellow arrows, but this does not necessarily mean that no failure took place. In Figure 10a, slightly elevated spectral amplitudes can be seen preceding the spectral amplitude of the main failure. These could be cracks forming, in the same way as for VF1 (Figure 8a), or small soil block falls, however, we have no visual observations to document this due to poor daylight conditions at the time. 

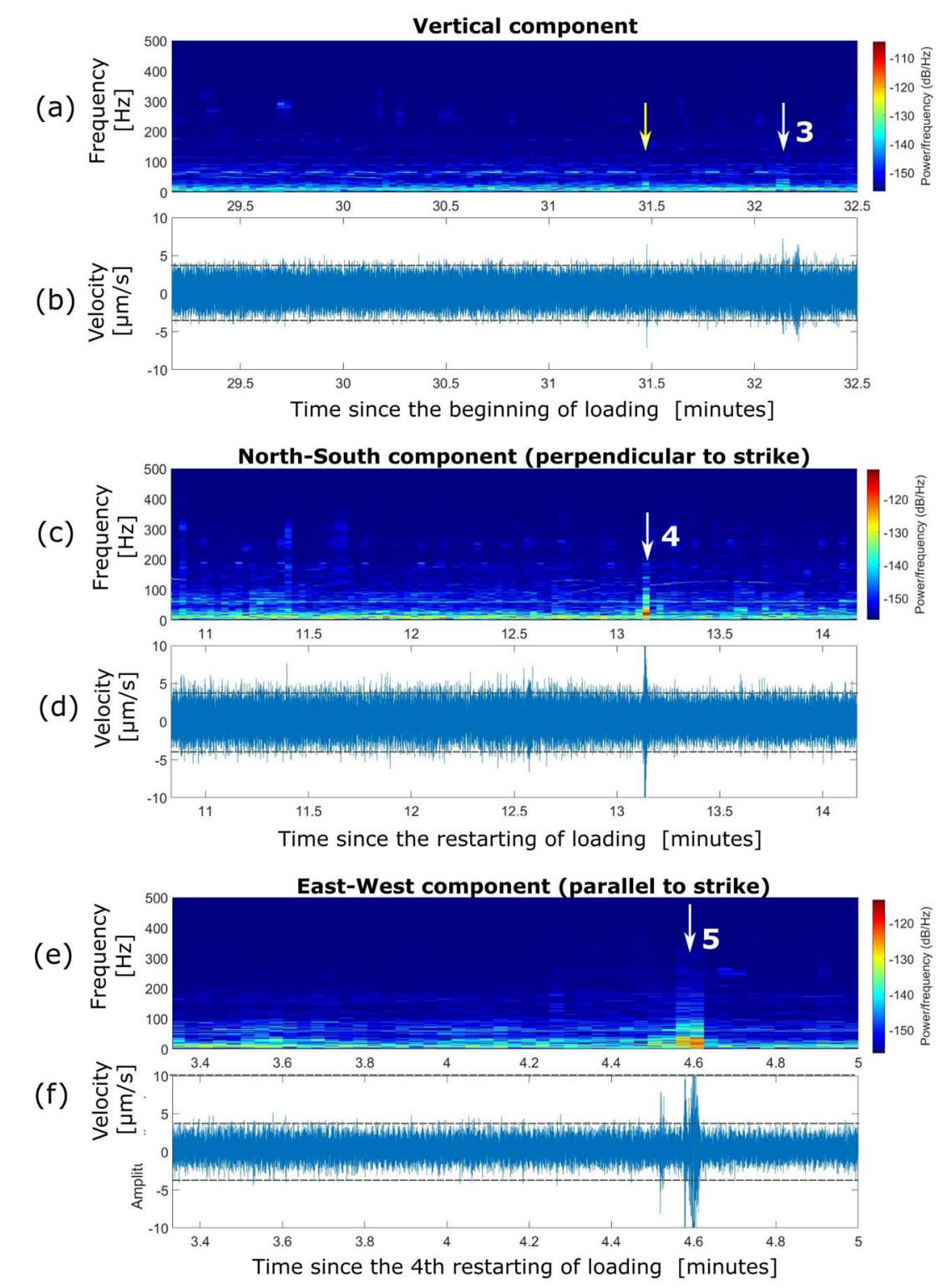

420 Figure 9. Spectrograms (a, c, e) and seismograms (b, d, f) of Soil Block failures for VF1 as recorded by the vertical component of sensor No.1. Occurrences of the observed Soil Block Falls are shown with white arrows. (a) Failure No. 3 in Fig. 6a,b distinguishable from noise at frequencies up to $60 \mathrm{~Hz}$. According to the field log, this was a very small soil block failing on already failed material. Annotated with a yellow arrow is an area of elevated spectral amplitude that could represent a similar failure event but which was not visually observed. (c) Failure No. 4 in Fig. 6a,b visible in the spectrogram at frequencies up to $160 \mathrm{~Hz}$. (e) Failures No. 5 and 6 in Fig. 6a,b distinguishable at frequencies up to $\sim 260 \mathrm{~Hz}$. These two failures took place one after the other within 4 seconds. This is why they appear as a single, rather wide column. Note that the origin $(0 \mathrm{sec})$ of the time axis in each spectrogram is different. Time resets to zero at the time of the first measurement of induced displacement following a gap in the data (see Fig 6a and the green intervals for the time occurrence of the 432 data gaps). 

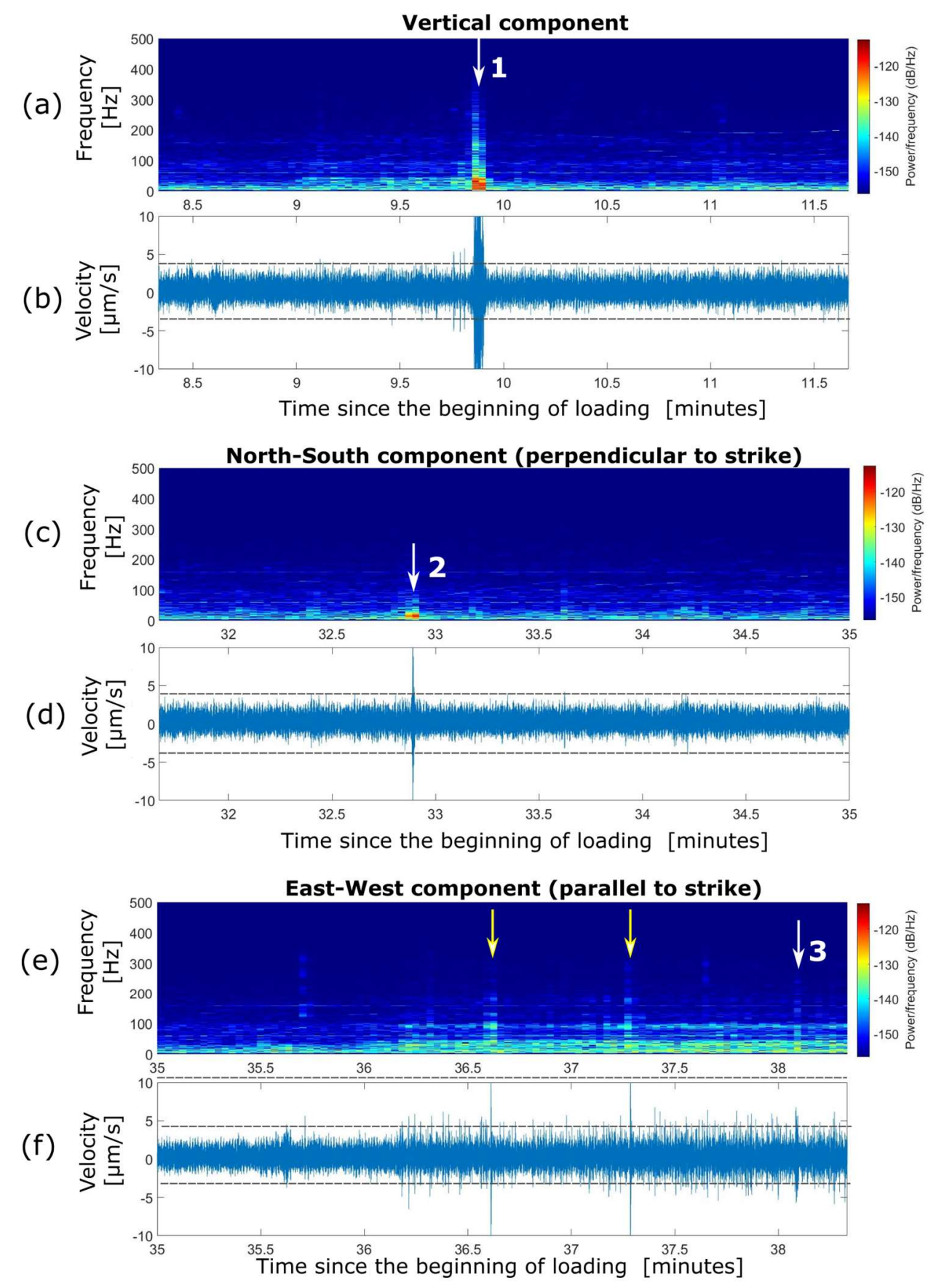

434 Figure 10. Spectrograms (a, c, e) and seismograms (b, d, f) of Soil Block failures for VF2 as 435 recorded by the vertical component of sensor No.1. Occurrences of the observed Soil Block 436 Falls are shown with white arrows. (a) Failure No. 1 in Fig. 6d, e is distinguishable from noise 437 at frequencies up to $\sim 350 \mathrm{~Hz}$. This was the biggest failure for VF2 and the third biggest 438 amongst all failure events. (b) Failure No. 2 in Fig. 6d, e distinguishable at frequencies up to $439 \sim 125 \mathrm{~Hz}$. (c) Failure No. 3 in Fig. 6c, d distinguishable at frequencies up to $\sim 250 \mathrm{~Hz}$. 440 Annotated with yellow arrows are elevated spectral amplitudes that could represent similar 441 failure events but which were not visually observed. 


\subsection{Spectral analysis of visually observed failures}

The failures that were visually observed in the field and identified in the seismic recordings with the use of spectrograms, are now analysed in the frequency domain in order to better understand the energy distribution up to the Nyquist frequency, i.e. up to $500 \mathrm{~Hz}$ in this study following the methodology described earlier in section 2.2.

\subsubsection{Crack Formation/Propagation}

Figure 11 shows the SNRdB spectrum of a 4 second long segment in the recordings of VF1 during which crack formation/propagation was observed. Since crack formation/propagation was observed as a continuous phenomenon in the field, the resulting SNR is effectively an average SNR, representing many crack events within these 4 seconds. As shown previously in fig. $3 \mathrm{~d}$, these are very small events occurring locally on a crack. These events can be considered as precursory events to the larger failures, e.g. the Soil Block Topple and Fall failures for VF1. We found that the maximum source-to-sensor distance that these cracks could be detected in the recordings was $10 \mathrm{~m}$ (fig. 11, black line).

Crack formation/propagation events were very weak, with the first visually observed soil burst found to be below background noise levels in the spectra. Their weak nature makes them very hard to identify and distinguish from noise. The SNR $\mathrm{dB}$ is consistently above zero for frequencies between $20 \mathrm{~Hz}$ and $350 \mathrm{~Hz}$ for the horizontal components. If we set a threshold of $\mathrm{SNR}_{\mathrm{dB}}=5$, this frequency range is narrower, between $125 \mathrm{~Hz}$ and $225 \mathrm{~Hz}$ (Fig. 11 , red and green lines).

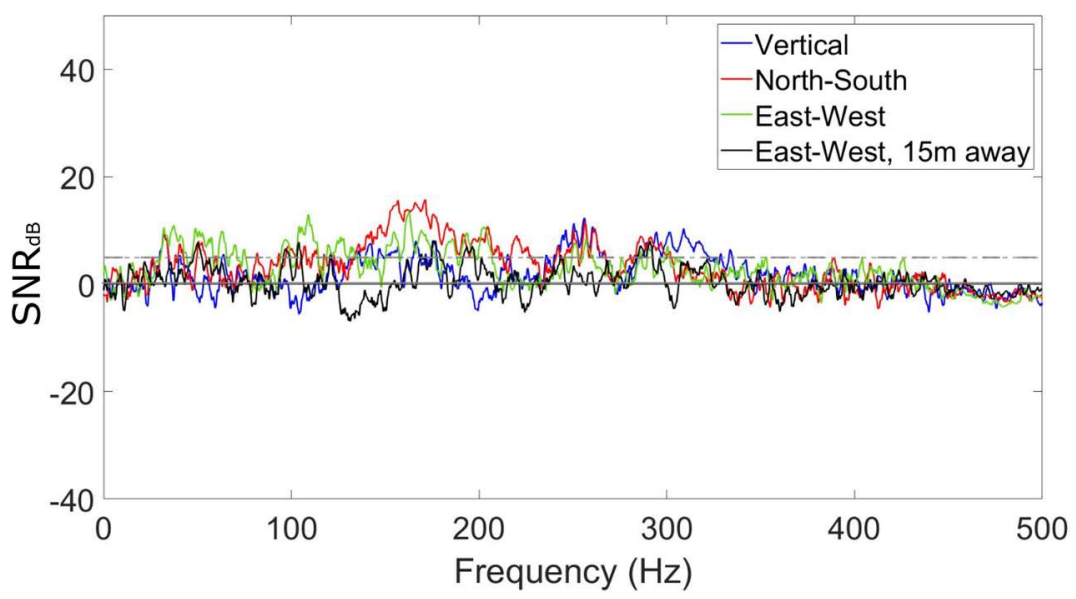

Figure 11. SNRdB spectrum of an observed soil burst that occurred prior to the first Soil topple and fall failure at VF1 using data as recorded by the vertical component (blue), the North-South (perpendicular to the vertical face strike; red) and the East-West component (parallel to the vertical face strike; green) of No.1 seismometer. The highest SNR $\mathrm{dB}$ values are found between $125 \mathrm{~Hz}$ and $225 \mathrm{~Hz}$. Also shown is the SNR spectrum of the same soil burst using data recorded by the East-West component of seismometer No2 at a distance of $15 \mathrm{~m}$ away from VF1 (for location see Fig. 2). The SNRdB value of 0 and 5, corresponding to SNR values of $1: 1$ and 3:1, are shown with a solid and dashed grey horizontal lines, respectively. 


\subsubsection{Soil block topple and fall}

Figure 12 presents the SNR $\mathrm{dB}_{\mathrm{B}}$ spectra of Failures 1 and 2 (Soil Block Topple and Fall) in Fig. $6 \mathrm{a}, \mathrm{b}$ of VF1 using data recorded by the vertical component of Seismometer No.1. The horizontal component data produced similar results for these two failures. All deployed sensors, the furthest being at a distance of $43.5 \mathrm{~m}$ from VF1 face, recorded these failures clearly. The SNR $\mathrm{dB}$ is quite high (signal almost 100 times more than the noise levels) throughout the whole frequency range examined at the monitoring distance of $10 \mathrm{~m}$. The largest values for the SNRdB are found within the range from $10 \mathrm{~Hz}$ to $25 \mathrm{~Hz}$ for both events.

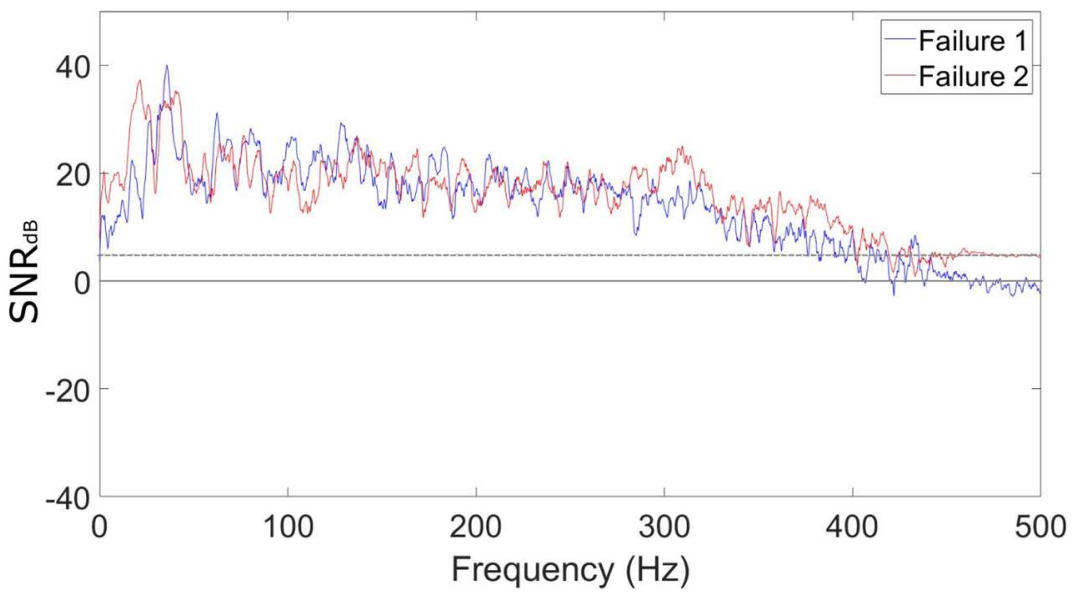

Figure 12. SNRdB spectra of Failures No 1 (a) and No 2 (b) in Fig.6a,b (Soil Block Topple and Fall) of VF1 from data recorded by seismometer No.1. The emitted energy can be clearly distinguished from noise over almost the whole frequency range up to Nyquist frequency, with the largest values for the SNR $\mathrm{dB}$ found within the range from $10 \mathrm{~Hz}$ and $25 \mathrm{~Hz}$ for both events. The SNRdB value of 0 and 5, corresponding to SNR values of 1:1 and 3:1, are shown with a solid and dashed grey horizontal lines, respectively.

\subsubsection{Soil block fall}

The SNRdB spectra of different Soil Block Fall events are presented in Figure 13. As mentioned in Section 3.3.2, the size of the soil block as well as the height of the fall and the ground conditions on which it falls (consolidated or unconsolidated) affect the degree over which the signal can be distinguished from the background noise levels.

We were able to visually observe three different sizes of soil blocks. Unfortunately, due to the nature of the experiment we were not able to measure the exact dimensions of the blocks, therefore we can only give a qualitative (small, medium, large) description of their size:

(1) Small events. The SNR $\mathrm{dB}$ is in general low, below 5 for almost the whole frequency range examined with the exception of the frequencies within the range $20 \mathrm{~Hz}$ to $50 \mathrm{~Hz}$ where the signal almost reached 10 times larger than the noise levels and for frequencies $200 \mathrm{~Hz}$ - 
$250 \mathrm{~Hz}$ (Figure 13a). This type of events could be distinguished from noise at other frequencies with differences up to $5 \mathrm{~dB}$, but this is not consistent among the different events. Such events were Failures No.3 and No.5 (see Fig.6a, b) observed for VF1. This type of event was found to be detectable in the recordings at a $20 \mathrm{~m}$ maximum distance from a 505 seismometer (black line in fig. 13a).

506 (2) Medium events. The SNR $\mathrm{dB}$ is above zero for all components up to frequencies of $300 \mathrm{~Hz}$, 507 with the signal being at least 3 times larger (and more than 100 times larger at frequencies 508 below $100 \mathrm{~Hz}$ ) for all components for frequencies up to $200 \mathrm{~Hz}$ (Figure $13 \mathrm{~b}$ ). Such events 509 were Failure No.4 (see Fig.6a, b) for VF1 and Failures No.2 \& No.3 (see Fig. 6d, e) for VF2. 510 This type of failure was recorded by all deployed sensors. As such, the detection threshold 511 was longer than $43.5 \mathrm{~m}$ which was the maximum horizontal distance between the 512 excavation front and the furthest away sensor (No.9 in Figure 2) in our experiment, 513 however at such a distance the SNR $\mathrm{dB}$ is below zero for frequencies $100 \mathrm{~Hz}$ and above (black 514 line, Figure 13b). 
(a)

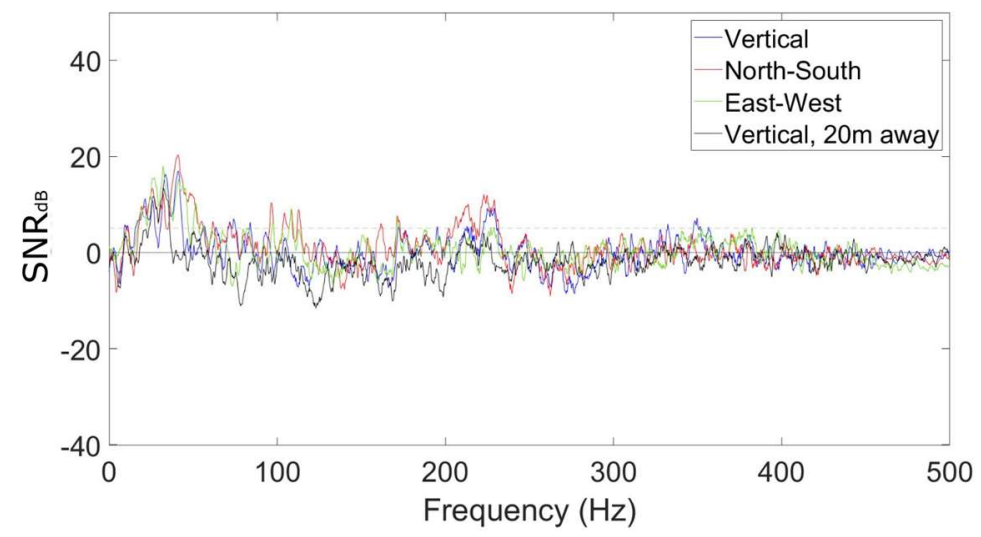

(b)

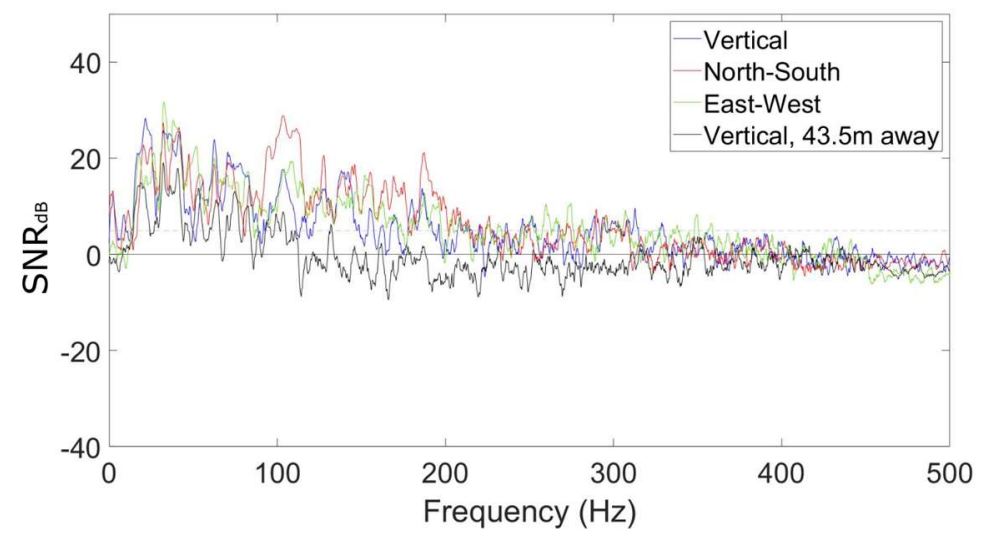

(c)

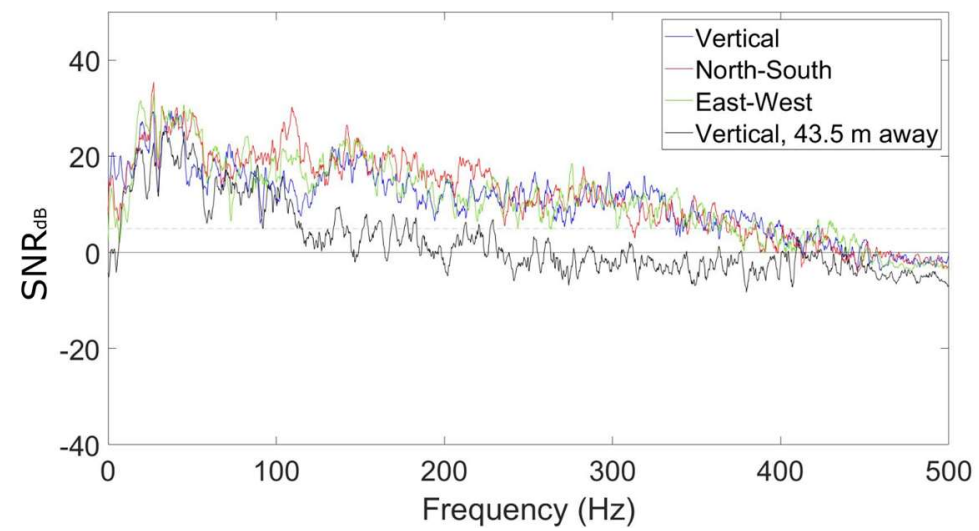

Figure 13. SNRdB spectra as recorded by all three components (blue: vertical, red: NorthSouth, green: East-West) of sensor No 1, at 10m horizontal distance from the excavation front. (a) a small Soil Block fall during VF1 induced failure. The spectrogram of this event is indicated by the white arrow in Figure 9a. When the horizontal distance reached $20 \mathrm{~m}$, the SNR spectrum for this event barely (with very few exceptions) exceeds 0 . (b) of a medium Soil Block fall during VF1 induced failure as recorded by all three components (blue: vertical, red: North-South, green: East-West) sensor No 1, at $10 \mathrm{~m}$ horizontal distance from the excavation front. When the horizontal distance reached $43.5 \mathrm{~m}$, the $S N R_{d B}$ spectrum for this event, as calculated from the data recorded at Sensor No 9, is below 0 for frequencies above $100 \mathrm{~Hz}$. (c) a large Soil Block fall during VF2 induced failure as recorded by all three 
components (blue: vertical, red: North-South, green: East-West) sensor No 1, at $10 \mathrm{~m}$ horizontal distance from the excavation front. The spectrogram of this event is shown in Figure 10a. When the horizontal distance reached $43.5 \mathrm{~m}$, the SNRdB spectrum for this event, as calculated from the data recorded at Sensor No 9, is consistently above 5 for frequencies up to $100 \mathrm{~Hz}$ and the signal remains distinguishable up to 225Hz. The SNRdB value of 0 and 5, corresponding to SNR values of $1: 1$ and 3:1, are shown with a solid and dashed grey horizontal lines, respectively.

(3) Large events. The SNR $\mathrm{dB}$ is well above 5 for all components up to frequencies of almost $400 \mathrm{~Hz}$, with the signal being at least 10 times larger (and almost 1000 larger between $20 \mathrm{~Hz}$ and $50 \mathrm{~Hz}$ ) for all components for frequencies up to $300 \mathrm{~Hz}$ (Figure 15). Such events were Failure No.1 (see Fig.6d, e) for VF2 and No6 (see Fig.6a, b) for VF1. Large events were recorded by all deployed sensors. The source-to-sensor distance detection threshold was found to be larger than $43 \mathrm{~m}$. It should be stated here, that we consider the numerical values of the SNRdB of the different sizes of Soil Block Falls, as well as the detection threshold distances, to be site specific, i.e. the geology and failure mechanism affect its values.

\section{Discussion}

Types of failures observed and recorded: Although microseismic monitoring has been used since the '90s for landslide monitoring, its applications to soft soils are limited due to unfavourable conditions: weak signals traveling through highly attenuating material. This is reflected on the small number of relevant published studies in the international literature. Our controlled experiment provided field scale documented evidence of the capabilities of microseismic monitoring to illuminate different phases in a landslide process: crack formation and propagation, soil block topple and fall and soil block fall failures, even when they correspond to very small volumes (less than $2.5 \mathrm{~m}^{3}$ ) of failed mass. We record these failures at maximum distances that vary from less than $10 \mathrm{~m}$ for crack formation/propagation to more than $40 \mathrm{~m}$ for soil block failures.

Frequency content of recorded failures: For the crack formation/propagation and the smaller soil block failure events that were visually observed and analysed, only the low frequency content of the signal is detected, as the higher frequencies were attenuated over the monitoring distances used in our experiment. All frequencies that we report here resulted from the analysis of recordings from seismometer No 1, which gave the signals with the highest SNR. This is a common approach, as in Provost et al (2017). We detect failure signals above noise levels at frequencies higher than $30 \mathrm{~Hz}$ (figures 11 and $13 \mathrm{a}$, b) with the exception of the large failure events that were clearly distinguishable below $30 \mathrm{~Hz}$ (figures 12 and 13c). We find that for larger failures, there are frequencies above $100 \mathrm{~Hz}$ and up to $380 \mathrm{~Hz}$ that are clearly distinguishable from noise at the short distance of $10 \mathrm{~m}$ used in our study. Published studies in clayey landslides report frequencies between $2 \mathrm{~Hz}$ and $125 \mathrm{~Hz}$ (Tonnellier et al., 2013; Provost et al., 2016; Vouillamoz et al. 2018). This difference is not characteristic of the source, but of the path and the monitoring distance. It is mainly due to attenuation and the fact that the monitoring distances in our study were considerably smaller to those reported in the literature: a few 10s of metres as opposed to 100s. The higher frequency range we identify in our study can potentially be useful in monitoring clayey slope instabilities at close source-to-receiver distances. 
Type of instrumentation used: In our study we used seismometers with a flat frequency response between $2 \mathrm{~Hz}$ to $100 \mathrm{~Hz}$. Our choice of instrumentation was based on best/common practice in the field of clayey landslide monitoring and the expected frequency band stated in the reviewed literature. Provost et al. (2017) and Vouillamoz et al. (2018) used very similar sensors, short-period seismometers (Lennartz 3Dlite and 1Dlite, flat frequency response between $1 \mathrm{~Hz}$ and $100 \mathrm{~Hz}$ ), and in Tonnellier et al (2013), the associated bandpass of the seismometers was between $0.1 \mathrm{~Hz}$ and $80 \mathrm{~Hz}$. The deployment geometries in all these studies were in tripartite arrays (following Joswig 2008, as we did in our study), and their observed events fell within the frequency range between $2 \mathrm{~Hz}$ and $125 \mathrm{~Hz}$. The upper bound of the frequency range $(380 \mathrm{~Hz})$ we identify is a finding of the research presented in this paper and could not have been known a priori. Due to our choice of instrumentations, the estimated spectral amplitude for frequencies above $100 \mathrm{~Hz}$ is rather an underestimation of the actual spectral amplitude, i.e. a lower bound of the spectral amplitude at these frequencies. This does not affect our conclusions. It should be highlighted, however, that our results refer to clays and for materials with larger grain sizes, these frequencies are likely to be different. The higher than expected frequency content identified in this study can have implications in (1) the choice of microseismic monitoring system. Commonly used microseismic systems have a flat response up to $100 \mathrm{~Hz}$. A different or additional system, for example use of $4.5 \mathrm{~Hz}$ geophones or accelerometers, to cover a wider range would be beneficial to capture the full range of events when short source-to-receiver distances are involved and (2) the automatic detection and classification algorithms that are solely based on unique seismic signals as reference. The latter, and the need to use signals of the same type but of different monitoring distances (and thus paths) has been highlighted previously by Provost et al. (2017).

Detection threshold and monitoring distances: As a detection threshold, we looked at SNR $\mathrm{dB}$ values above zero, with a value of SNR $\mathrm{dB}$ higher than 5 (corresponding to SNR 3:1) indicating a strong signal. The latter is a somewhat conservative threshold. In their study, Tonnellier et al. (2013) set a threshold of SNR equal to 2:1 for the detection of signals, while in Provost et al. (2017) the ratio of the seismic signal spectrum over the noise signal spectrum for a signal to be detected should be equal to 1.5. Despite such a conservative threshold, the signals are still distinguishable. The noise levels at our site were considered higher than in rural areas but still within the boundaries defined by the New Low-Noise Model (NLNM) and the New High-Noise Model (NHNM) suggested by Peterson (1993) for noise levels worldwide. The noise levels at our site are rather closer to the NHNM. To be consistent with our data (in units of velocity), Figure 14 shows the PSD values that correspond to velocity rather than acceleration. The corresponding values for the NLNM and NHNM for velocities were taken from Tables 4.1 and 4.2 in Borman (2012).

Where observation of weak precursory signals is key, seismometers should be located as close as possible behind the expected or existing failure plane (in plan view) and within a short distance $(<15 \mathrm{~m}$ if at high attenuation ground such as the site of this study). 


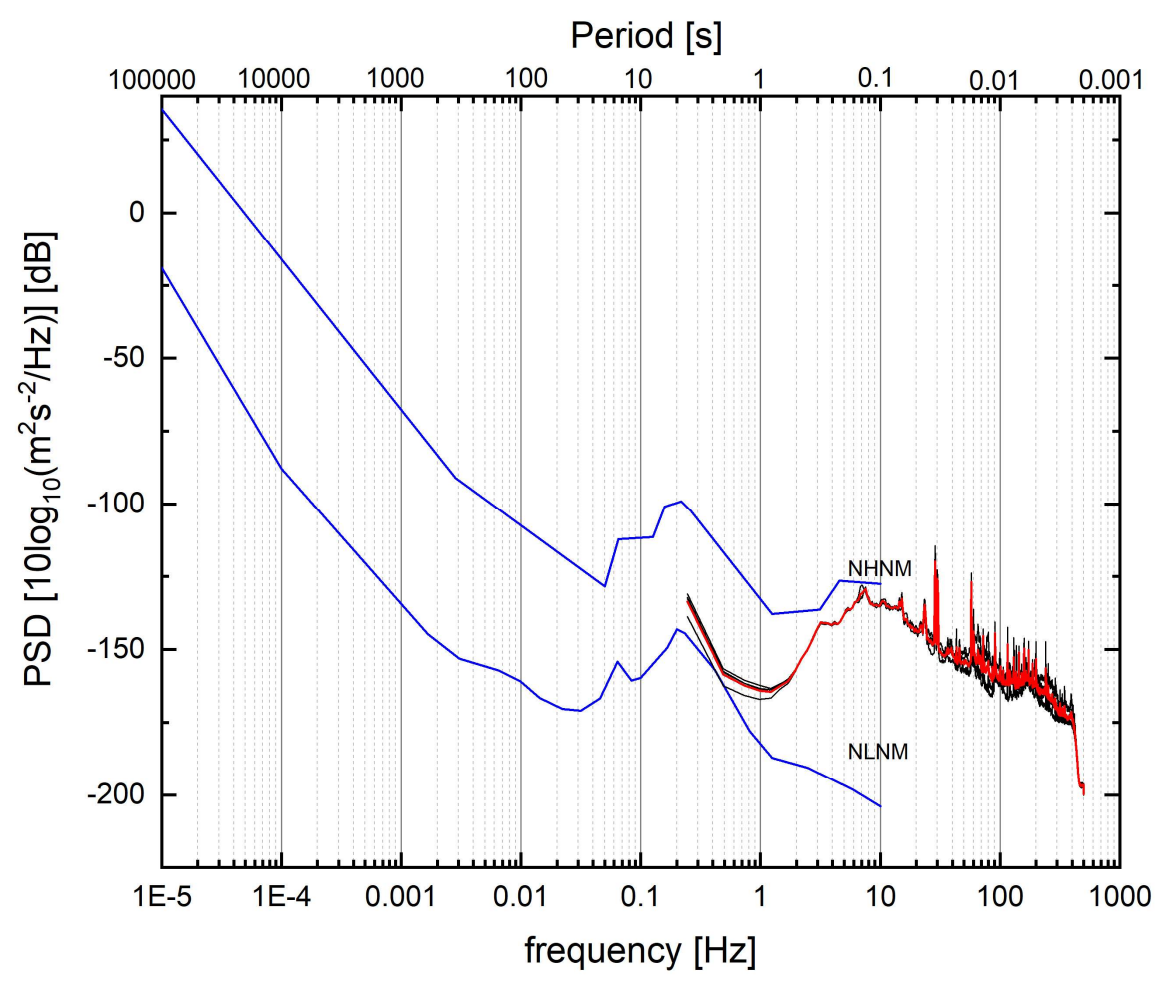

609

610

611

612

613

614

615

616

617

618

619

620

621

622

623

624

625

626

627

628

Figure 14. Characteristic (average) PSD of the background noise (red line) at the field site from data recorded by the linear array consisting of seismometers No 2, 3, 4 and 5 and their corresponding PSDs (black lines). For comparison, the NLNM and NHNM are also provided.

With site conditions such as in this study, i.e. high attenuation and relatively high noise levels, weak events such as crack formation, were detectable at distances just over $10 \mathrm{~m}$, while large events like soil block topple and falls were detectable at distances of at least $43.5 \mathrm{~m}$. All failure events presented here were of exceptionally small volumes $\left(<2.5 \mathrm{~m}^{3}\right)$. For larger volumes, the emitted energy is larger and as such, the distances over which a failure event could be detected should be larger despite longer monitoring distances, e.g. $500 \mathrm{~m}$ as in Vouillamoz et al (2018).

Figure 15 shows how the SNR $\mathrm{dB}$ changes with distance on our field site. To simplify the figure we applied a 14-point moving average. We chose one of the topple and fall signals which was the strongest recorded by all the seismometers of the linear array. From Figure 15 it can be seen that the SNRdB value clearly falls below 5 (SNR 3:1) for the first time for frequencies above $80 \mathrm{~Hz}, 160 \mathrm{~Hz}, 275 \mathrm{~Hz}$, and $380 \mathrm{~Hz}$ at distances $43.5 \mathrm{~m}, 30 \mathrm{~m}, 20 \mathrm{~m}$ and $15 \mathrm{~m} / 10 \mathrm{~m}$, respectively. We were not able to study the effect of attenuation over longer distances for the other types of failure as they were only recorded by seismometers at $10 \mathrm{~m}$ and $15 \mathrm{~m}$. 


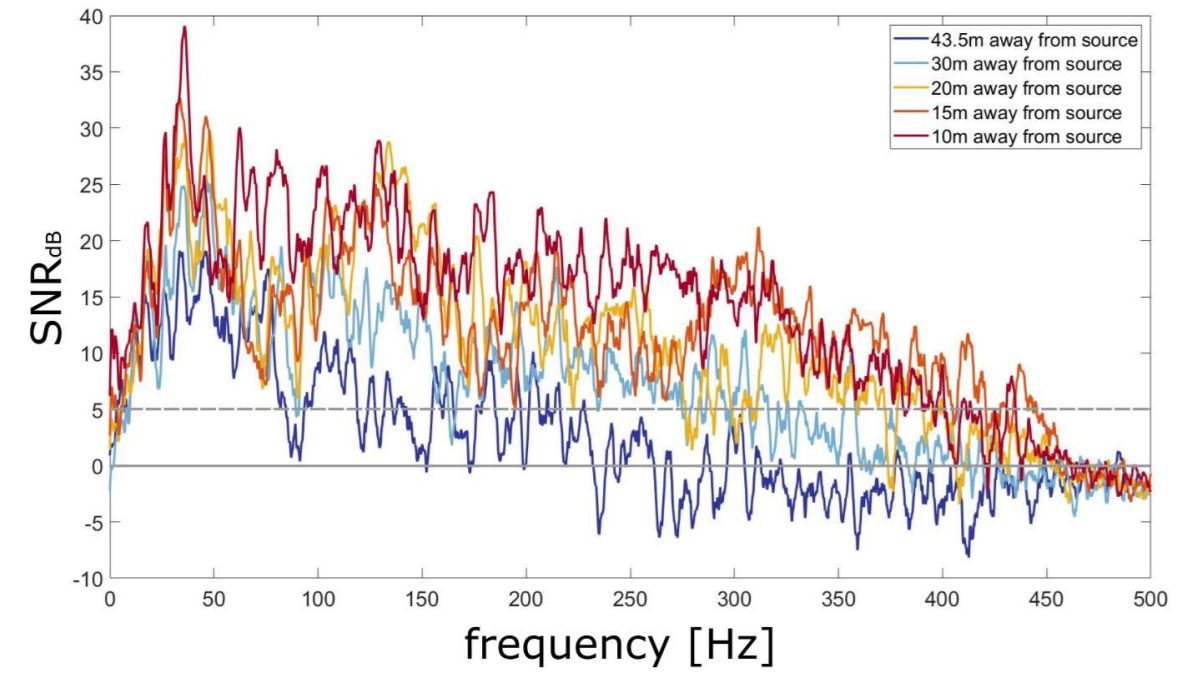

Figure 15. SNR spectra for failure No 1 in fig. 6a, b using data from the linear array (seismometers No 2, 3, 4 and 5, see fig.2 for location).

The locations and spacing required between seismometers for a monitoring system of a large slope would depend on the location of vulnerable targets, the site access restrictions and the size of the failing mass volume that poses a significant hazard to infrastructure and well-being. For large slopes, monitoring distances of less than $10-15 \mathrm{~m}$ from the failing mass might be difficult to realise, especially if there is a limited number of available seismometers, thus small scale crack events, like those in our study, might remain undetected. If cost is not a prohibiting factor, a geomorphological and geomechanical study could identify "hot spots" where failures could start occurring. Such an approach could minimize the area in need of monitoring, thus allowing for optimised deployment of the monitoring network. Generally, such events for large slopes might be insignificant. What could be classified as a precursory event in these cases are the bigger failure events we observed, which should be possible to detect at longer distances, i.e. a few 10s of metres.

Small receiver to source distances can be implemented in the case of monitoring of embankments where the overall dimensions and volume of the structure are significantly smaller and where the detection of small crack formation is important. For the monitoring of embankments or small road/rail cuts we would recommend a denser monitoring network with seismometers deployed within $10 \mathrm{~m}$ from each other. This is consistent with the distance recommendations by Vouillamoz et al. (2018). For embankments, this would inevitably mean that the instrumentation is deployed on what could potentially be failing ground, however, the potential of detecting material deterioration, e.g. internal erosion, at the very early stages, outweighs the risk of damaged instrumentation, which for this case is considerably small.

Detection in the frequency domain: It is worth noting that the crack formation/propagation events and the smaller soil block failures in our study had amplitudes in the time domain that were below or just above the noise amplitude (figure 6b). This would make their recording and subsequent detection very difficult, if not impossible, when using a triggering recording mode and detection methodologies based on 
the time domain. On the contrary, such events were present in the frequency domain, therefore, a detection approach based in the frequency domain is recommended in automatic detection from continuous microseismic recordings.

Cracks can be considered a precursor to larger failure events and ultimately, may link up to form the failure plane, thus it is important that they can be detected. Our results provide evidence of significant potential for microseismic monitoring networks to constitute a complimentary part of a monitoring system for early detection of failures in locations of known and anticipated landslide risk. However, in order for them to be effective, more experiments like the one described in this study are required to establish statistically significant values for the seismic signatures of different types of failure events. Currently, there is no technology that allows early enough identification of material deterioration in earthen structures. Unfortunately, any weakness becomes apparent either just before or during failure with severe consequences at times, e.g. the recent failure of the Whaley Bridge dam in England with more than 1,500 people evacuated (August 2019) and the derailment of a passenger train in Scotland due to a landslide, resulting in loss of life (August 2020).

To our knowledge, no other study exists in the international literature that discusses the seismic signature of ground-truthed slope failure at field scale, from crack propagation to full failure, within the seismic frequency range (up to $500 \mathrm{~Hz}$ ) and without the use of acoustic emissions (sampling rates of the order of kHz, e.g. Smith et al., 2014; Deng et al. 2019). From our spectral analysis we have evidence of the possible occurrence of numerous failure events (for example, those indicated by yellow arrows in Figures 9a and 10e) other than those we have visually confirmed in the field. For the visually confirmed failure events in the field, due to the small number of events, it was not possible to statistically discriminate between crack formation/propagation and small soil falls, based only on their spectral characteristics. Hence, labeling of the recorded signals was solely based on visual inspection. Neither could we robustly discriminate between medium/large soil block falls and soil block topple and fall using only the seismic recordings. However, this is not a limitation of the study. Our results could be used as the basis for further and more in-depth analysis aimed at identifying specific classifiers for automated discrimination between different slope failure types.

\section{Conclusions}

We provide evidence that it is possible to record seismic signals of crack propagation preceding larger, more complex failures involving soil block topples and falls in clayey soils. Detection is possible at short monitoring distances, a few metres for cracks and a few 10s metres for soil block topples and falls. At short monitoring distances (up to $30 \mathrm{~m}$ ), our results revealed an extended frequency range $(20 \mathrm{~Hz}$ to $275 \mathrm{~Hz})$ over which failures in clayey soils as small as $2.5 \mathrm{~m}^{3}$ can be detected over the background noise. This has implications in the choice of monitoring instrumentation as well as in the development of automated detection and classification algorithms that are commonly based on frequencies up to $100 \mathrm{~Hz}$. Our study was limited to one experiment and number of visually observed failures of different types, but if more experiments could be carried out to provide a larger number of visually observed failures, a full spectral characterization for each failure type is possible. All the failures observed during our experiment were of very small volumes compared to those reported in 
the literature. This makes them similar to precursory events to larger failures. Our research provides ground-truthed evidence that microseismic monitoring can act as a temporary monitoring method, deployed adjacent to a soft soil dominated slope, for assessing its kinematic characteristics even at site locations with high noise levels such as those encountered close to urban areas or at hydroelectric schemes, providing short monitoring distances can be achieved. For example, microseismic monitoring could complement existing geodetic and geotechnical monitoring networks established to assess the structural integrity of earthfill dams and flood embankments. Most importantly, our study provides the first data on some spectral characteristics of very small failures, validated against visual observations of the failure type, on which future automatic identification and classification algorithms could be based.

\section{Acknowledgments}

The authors would like to thank Dr. Gregório Luís Silva Araújo for his advice and help regarding the experimental set-up, and the company "EMBRE Engenharia" for providing the hardware and manpower needed to conduct the experiments. Also, many thanks to Jorge de la Rosa Gonzalez, Marcelo Alejandro Lano Serna, Diego Alexander Ocampo, Raydel Lorenzo Reinaldo, Julián Buriticá García and Eduardo Botero, for their assistance during the field experiments. This work was funded by the University of Strathclyde, EU/FP7 - GeoExcel project (FP7-People-IRES-2008) and the University of Brasilia. This paper benefited from the comments and suggestions of the Editor and two anonymous reviewers.

\section{Author Statement}

GY: Conceptualization, Methodology, design and carry out field experiment, Data Analysis, Interpretation, Visualisation, Writing - Original draft preparation, SP: Methodology, Interpretation of results, Visualisation, Supervision, Writing - Reviewing, Editing and finalizing manuscript. HEMC: Design and carry out Field experiment, Supervision. RL: Methodology, Interpretation of results, Supervision, Writing - Reviewing, Editing.

\section{References}

Amitrano, D., Grasso, J. R. ,Senfaute, G. , 2005. Seismic precursory patterns before a cliff collapse and critical point phenomena, Geophys. Res. Lett. 32, 8. https://doi.org/ 10.1029/2004GL022270.

Arosio, D., Longoni, L., Papini, M., Zanzi, L., 2015. Analysis of Microseismic Activity Within Unstable Rock Slopes, in: Scaioni, M. (Ed.), Modern Technologies for Landslide Monitoring and Prediction. Springer Natural Hazards, Springer, Berlin, Heidelberg, pp. 141-154.

Barla, G.B., Antolini, F., Barla, M., Mensi, E., Piovano, G., 2010. Monitoring of the Beauregard landslide (Aosta Valley, Italy) using advanced and conventional techniques. Eng. Geol. 116, 218-235. https://doi.org/10.1016/j.enggeo.2010.09.004.

Bertello, L., Berti, M., Castellaro, S., Squarzoni, G., 2018. Dynamics of an Active Earthflow Inferred From Surface Wave Monitoring. J Geophys Res-Earth Surface 123, 18111834. https://doi.org/10.1029/2017JF004233. 
Bormann, P., 2012. New Manual of Seismological Observatory Practice (NMSOP-2), Potsdam : Deutsches GeoForschungszentrum

GFZ;

IASPEI. https://doi.org/10.2312/GFZ.NMSOP-2

Dammeier, F., Moore, J. R., Hammer, C., Haslinger, F., Loew, S., 2016. Automatic detection of alpine rockslides in continuous seismic data using hidden Markov models. J. Geophys. Res. Earth Surf. 121, 351-371., https://doi.org/10.1002/2015JF003647.

Fiolleau, S., Jongmans, D., Bièvre, G., Chambon, G., Baillet, L., Vial, B., 2020. Seismic characterization of a clay-block rupture in Harmalière landslide, French Western Alps. Geophys J Int, 221(3), 1777-1788. https://doi.org/10.1093/gji/ggaa050.

Fischer, T., Kühn, D., Roth, M. 2020. Microseismic events on the Åknes rockslide in Norway located by a back-projection approach. J. Seismol. 24, 55-74. https://doi.org/10.1007/s10950-019-09884-5.

Gigli, G., Fanti, R., Canuti, P., Casagli, N., 2011. Integration of advanced monitoring and numerical modeling techniques for the complete risk scenario analysis of rockslides: the case of Mt. Beni (Florence Italy). Eng. Geol. 120, 48-59. https://doi.org/10.1016/i.enggeo.2011.03.017.

Guinau, M., Tapia, M., Pérez-Guillén, C., Suriñach, E., Roig, P., Khazaradze, G., Torné, M., Royán, M.J., Echeverria, A., 2019. Remote sensing and seismic data integration for the characterization of a rock slide and an artificially triggered rock fall. Eng. Geol. 257, 105113. https://doi.org/10.1016/j.enggeo.2019.04.010

Helmstetter, A., Garambois, S., 2010. Seismic monitoring of Séchilienne rockslide (French Alps): Analysis of seismic signals and their correlation with rainfalls. J. Geophys. Res. 115, F3. https://doi.org/10.1029/2009JF001532.

Jongmans, D., Bièvre, G., Renalier, F., Schwartz, S., Beaurez, N., Orengo, Y., 2009. Geophysical investigation of a large landslide in glaciolacustrine clays in the Trièves area (French Alps). Eng. Geol. 109(1-2), 45-56. https://doi.org/10.1016/i.enggeo.2008.10.005.

Joswig, M., 2008. Nanoseismic monitoring fills the gap between microseismic networks and passive seismic. First break, 26 (6), 117-124. https://doi.org/0.3997/13652397.26.1288.28413.

Lévy, C., Baillet, L., Jongmans, D., Mourot, P., Hantz, D., 2010. Dynamic response of the Chamousset rock column (Western Alps, France). J Geophys Res-Earth 115, F04043. https://doi.org/10.1029/2009JF001606

Lévy, C., Jongmans, D., Baillet, L., 2011. Analysis of seismic signals recorded on a prone-tofall rock column (Vercors massif, French Alps). Geophys. J. Int. 186, 1, 296-310. https://doi.org/10.1111/j.1365-246X.2011.05046.x.

Li, M., Zhao, Y., 2014. Chapter 8 - Hydrocarbon detection technology, in: Li, M., Zhao, Y. (Eds.), Geophysical Exploration Technology, Applications in Lithological and Stratigraphic Reservoirs, Elsevier, pp. 221-237. https://doi.org/10.1016/B978-0-12-4104365.00008-3. 
Mainsant, G., Larose, E., Brönnimann, C., Jongmans, D., Michoud, C., Jaboyedoff, M., 2012. Ambient seismic noise monitoring of a clay slope: Toward failure prediction. J. Geophys. Res. 117, F1. https://doi.org/10.1029/2011JF002159.

Otálvaro, I., F., Neto, M., P., C., Caicedo, B. 2015. Compressibility and microstructure of compacted laterites, Transportation Geotechnics, 5, 20-34. https://doi.org/10.1016/i.trgeo.2015.09.005.

Peterson, J., 1993. Observations and modeling of seismic background noise. Rapport technique Open File Report 93-332, USGS. https://doi.org/10.3133/ofr93322.

Press, W.H., Flannery, B.P., Teukolsky, S.A., Vetterling, W.T., 1992. Numerical recipes in C: the art of scientific computing, third ed. Cambridge University Press, Cambridge. ISBN: 9780521880688.

Provost, F., Hibert, C., Malet, J.-P., 2017. Automatic classification of endogenous landslide seismicity using the Random Forest supervised classifier. Geophys. Res. Lett. 44, 113120. https://doi.org/10.1002/2016GL070709.

Senfaute, G., Duperret, A., Lawrence, J.A., 2009. Micro-seismic precursory cracks prior to rock-fall on coastal chalk cliffs: a case study at Mesnil-Val, Normandie, NW France. Natural Hazards \& Earth System Sciences, 9, 1625-1641. https://doi.org/ 10.5194/nhess-9-1625-2009.

Silva, C., P., L., da, 2011. Three-dimensional mapping of geotechnical Northwestern Sector of Brasília. PhD Thesis, University of Brasilia, Brazil. https://repositorio.unb.br/handle/10482/7730.

Smith, A., Dixon, N., Meldrum, P., Haslam, E., Chambers, J., 2014. Acoustic emission monitoring of a soil slope: Comparisons with continuous deformation measurements. Geotech Lett. 4(4), 255-261. http://doi.org/10.1680/geolett.14.00053.

Spillmann, T., Maurer, H., Green, A.G., Heincke, B., Willenberg, H., Husen, S., 2007. Microseismic investigation of an unstable mountain slope in the Swiss Alps. J. Geophys. Res. 112, B7. https://doi.org/10.1029/2006]B004723.

Tonnellier, A, Helmstetter, A., Malet, J-P., Schmittbuhl, J., Corsini, A., Joswig, M., 2013. Seismic monitoring of soft-rock landslides: the Super-Sauze and Valoria case studies. Geophys. J. Int. 193(3), 1515-1536. https://doi.org/10.1093/gji/ggt039.

Tosi, P., Sbarra, P., De Rubeis, V., 2012. Earthquake sound perception. Geophys. Res. Lett. 39, L24301. https://doi.org/10.1029/2012GL054382.

Vouillamoz, N., Rothmund, S., Joswig, M., 2018. Characterizing the complexity of microseismic signals at slow-moving clay-rich debris slides: the Super-Sauze (southeastern France) and Pechgraben (Upper Austria) case studies. Earth Surf. Dynam. 6, 525-550. https://doi.org/10.5194/esurf-6-525-2018.

Walter, M., Arnhardt, C., Joswig, M., 2012. Seismic monitoring of rockfalls, slide quakes, and fissure development at the Super-Sauze mudslide, French Alps. Eng. Geol. 128, 12-22. https://doi.org/10.1016/j.enggeo.2011.11.002. 
821 Welch, P.D., 1967. The use of fast Fourier transform for the estimation of power spectra: a

822

823

824

825

826

827

828

829 method based on time averaging over short, modified periodograms. IEEE Transactions on audio and electroacoustics 15(2), 70-73. https://doi.org/ 10.1109/TAU.1967.1161901.

Whiteley, J.S., Chambers, J.E., Uhlemann, S., Wilkinson, P.B., Kendall, J.M., 2019. Geophysical Monitoring of Moisture-Induced Landslides: A Review. Reviews of Geophysics 57(1), 106-145. https://doi.org/10.1029/2018RG000603.

Zimmer, V.L., Sitar, N., 2015. Detection and location of rock falls using seismic and infrasound sensors. Eng. Geol. 193, 49-60. https://doi.org/10.1016/j.enggeo.2015.04.007. 